
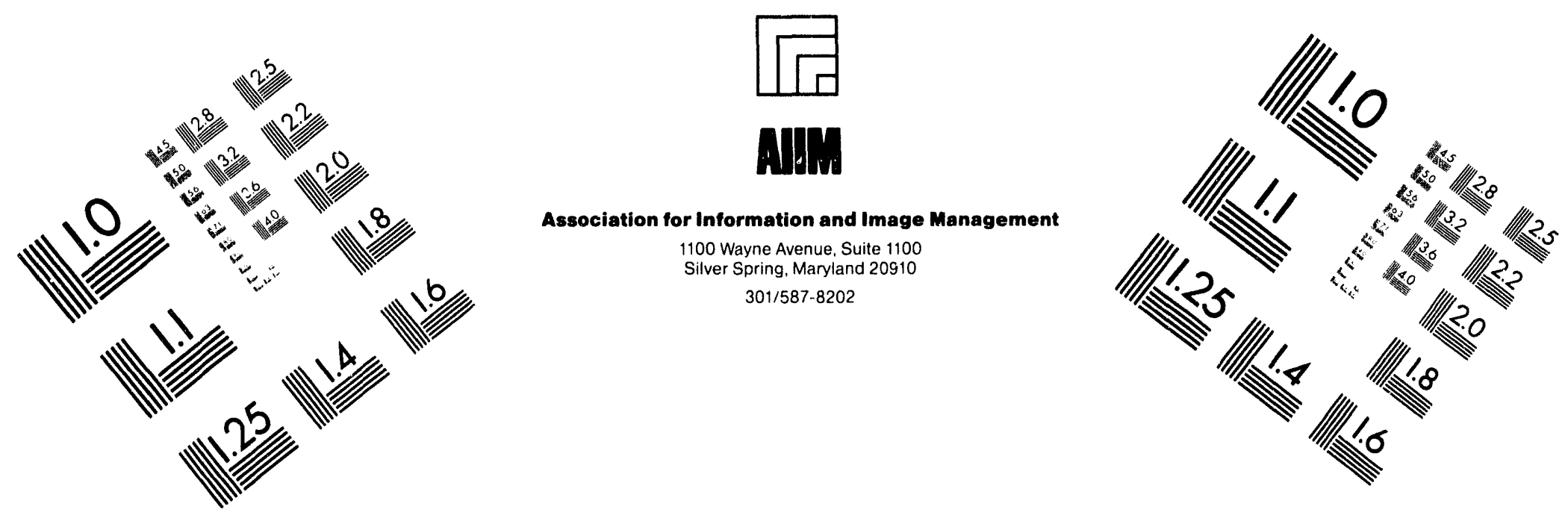

Centimeter

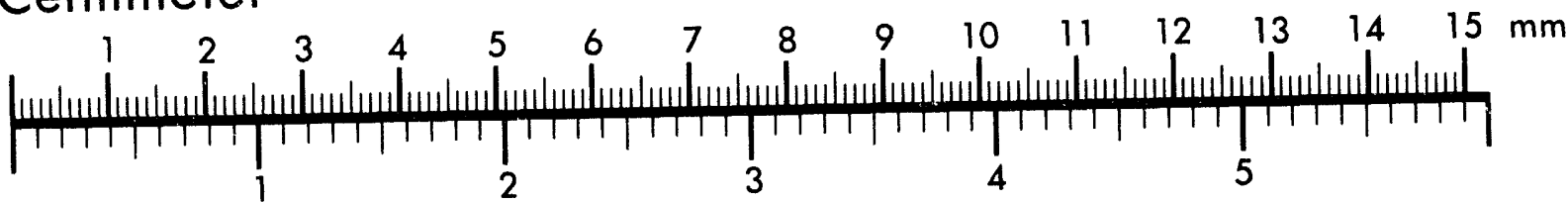
Inches
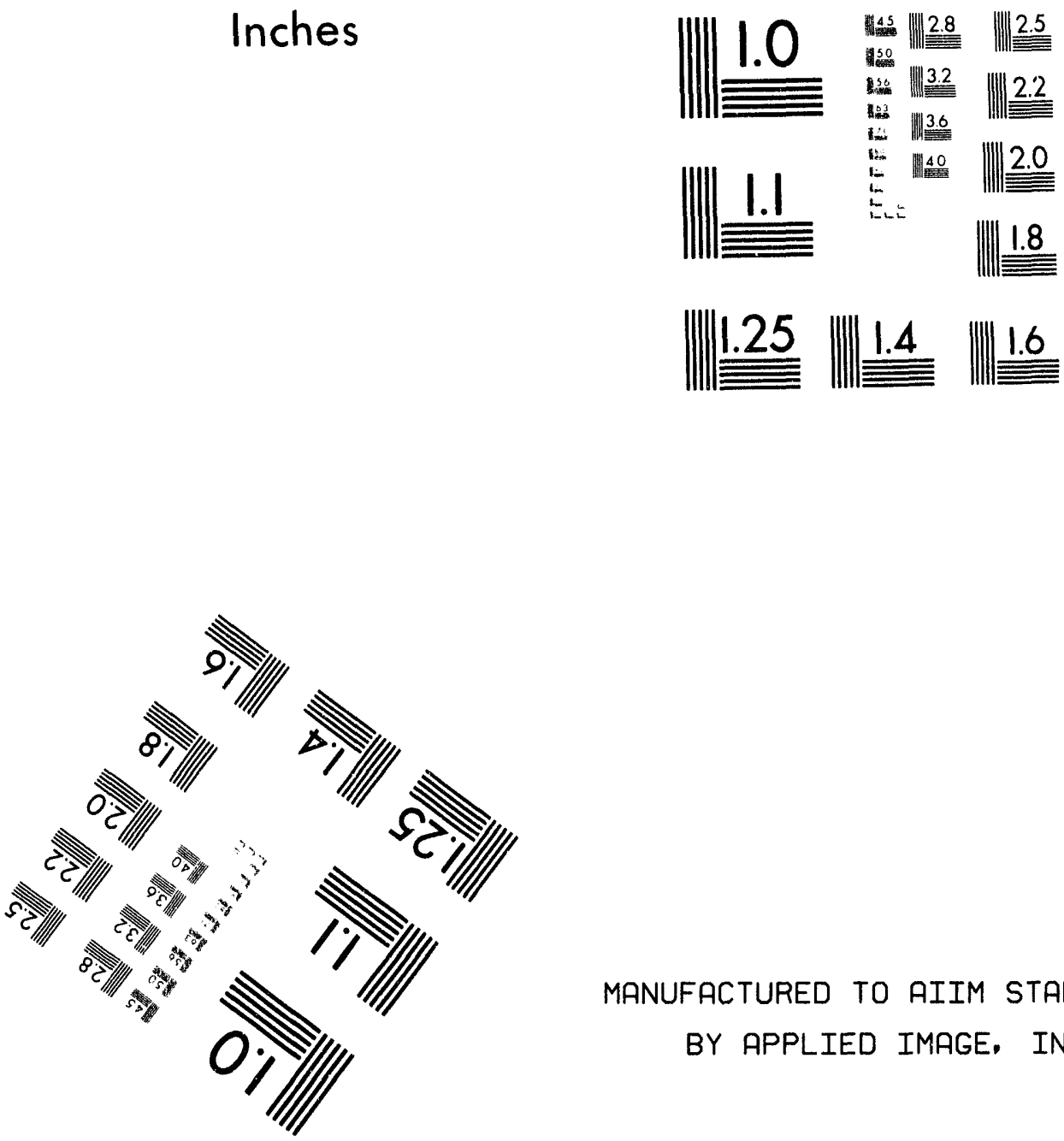

MANUFACTURED TO AIIM STANDARDS

BY APPLIED IMAGE, INC.

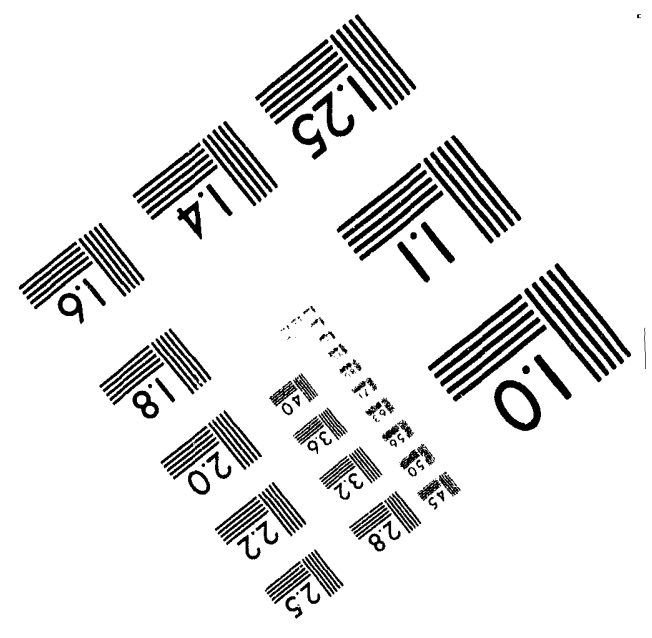



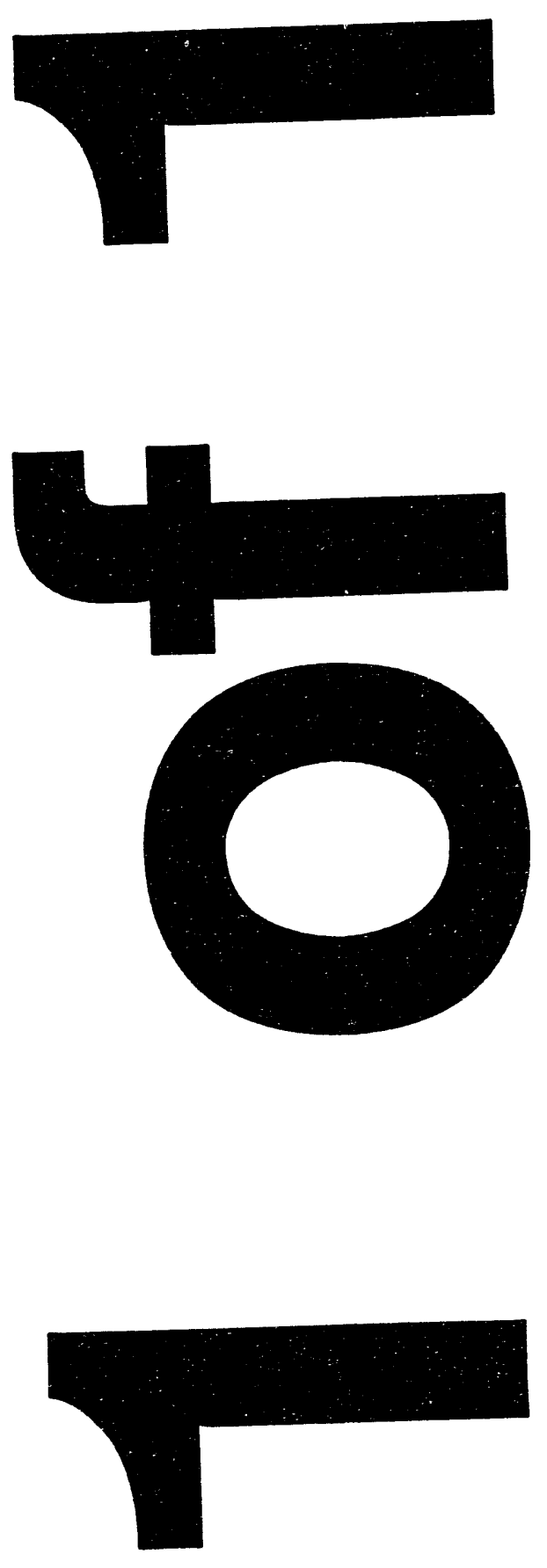


\title{
$\frac{1}{5} 604955$
}

UCRL-ID-115754

\section{Mixed Waste Treatment Project: Computer Simulations of Integrated Flowsheets}

\author{
Laura J. Dietsche
}

December 1993

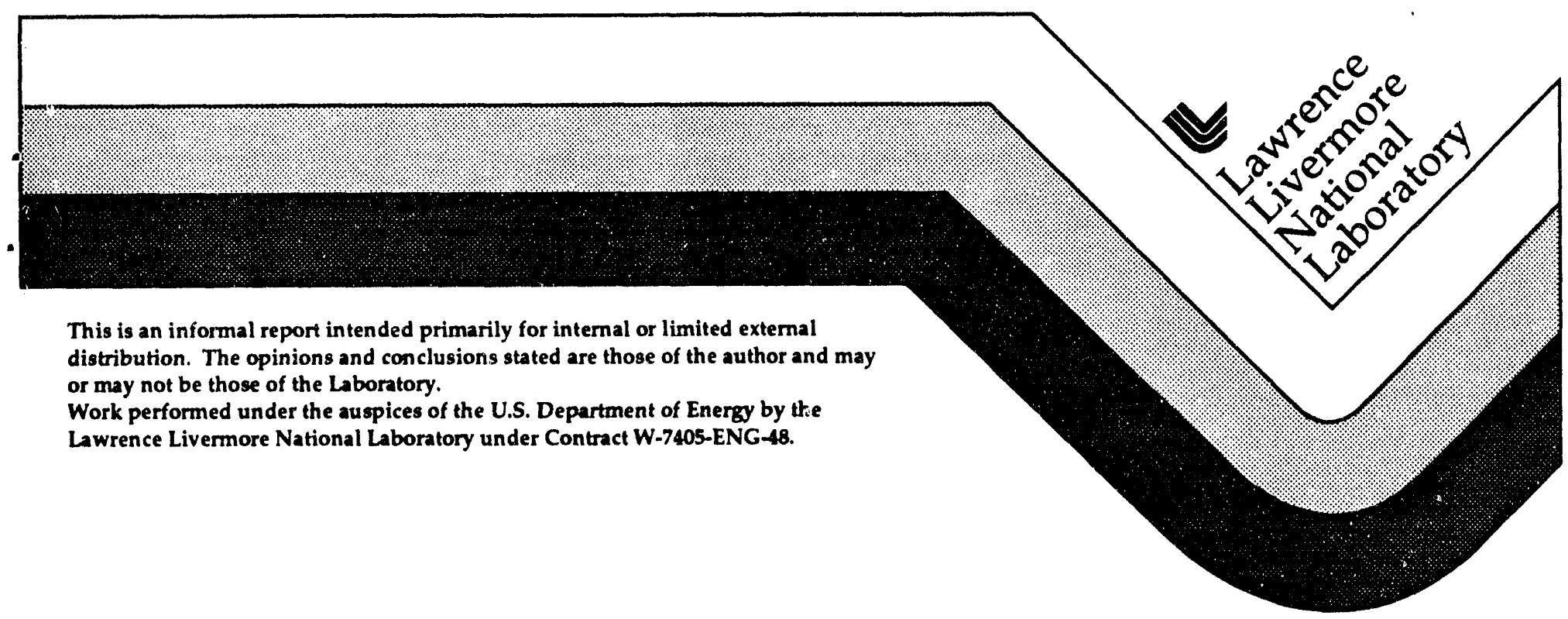




\section{DISCLAIMER}

This document was prepared as an account of work sponsored by an agency of the United States Government. Nejther the Jinited States Government nor the University of California nor any of their employees, makes any warranty, express or implied, or assumes any legal liability or responsibility for the accuracy, completeness, or usefulness of any information, apparatus, produch, or process disclosed, or represents that its use would not infringe privately owned rights. Reference herein to any specific commercial products, process, or service by trade name, trademark, manufacturer, or otherwise, does not necesaraily constitute or imply its endorsement, recommendation, or favoring by the United States Government or the University of California. The views and opinions of authors expressed herein do not necessarily state or refect those of the United States Government or the University of California, and shall not be used for advertising or product endorsement purposes.

This report has been reproduced directly from the best available copy.

Available to DOE and DOE contractors from the Ofice of Scientific and Technical Information P.O. Box 62, Oak Ridge, TN 37831

Prices available from (615) 576-8401, FTS 626.8401

Available to the public from the National Technical Information Service

US. Department of Commerce 5285 Port Royal Rd.

Springfield, VA 22161 


\title{
MIXED WASTE TREATMENT PROJECT: COMPUTER SIMULATIONS OF INTEGRATED FLOWSHEETS
}

\author{
Laura J. Dietsche \\ Lawrence Livermore National Laboratory
}

\section{INTRODUCTION:}

The disposal of mixed waste, that is waste containing both hazardous and radioactive components, is a challenging waste management problem of particuiar concern to DOE sites throughout the United States. Traditional technologies used for the destruction of hazardous wastes need to be re-evaluated for their ability to handle mixed wastes, and in some cases new technologies need to be developed.

The Mixed Waste Treatment Project (MWTP) was set up by DOE's Waste Operations Program (EM.30) to provide guidance on mixed waste treatment options. One of MWTP's charters is to develop flowsheets for prototype integrated mixed waste treatment facilities which can serve as models for sites developing their own treatment strategies. Evaluation of these flowsheets is being facilitated through the use of computer modelling. The objective of the flowsheet simulations is to provide mass and energy balances, product compositions, and equipment sizing (leading to cost) information. The modelled flowsheets need to be easily modified to examine how alternative technologies and varying feed streams effect the overall integrated process.

A number of commercially available software packages can model steady state chemical processes. They perform complex mass and energy balances using thermodynamic equilibrium algorithms, and can handle multiple recycle streams. They contain built-in codes which simulate typical processing equipment such as distillation columns, heaters, reactors, pumps, and filters. Most are also capable of accessing usergenerated FORTRAN codes. The individual pieces of equipment are "piped" together to create the overall flowsheet. Modification can be made by changing equipment blocks, redefining feedstreams, and repiping the connecting streams. One advantage of these commercial software packages is the large chemical property database supplied with them (typically containing over 2000 components). Foi components not in the database, the user can usually supply his own data.

One such commercially available simulation program is ASPEN PLUS (hereafter referred to as ASPEN), marketed by Aspen Technology, Inc. ASPEN contains all of the features mentioned above; it also has the ability to model electrolyte chemistry, solids 
handling operations, and reactive distillation. It comes with a graphical interface to simplify flowsheet creation, and an expert guidance system to help complete all of the required specifications. An ASPEN costing program is also available which interfaces with the simulation program to perform economic evaluations of the modelled processes. A simulation program, such as ASPEN, is well suited to the goals of the MWTP modelling project.

The first MWTP flowsheet to be modelled using ASPEN was the so-called baseline flowsheet. Details for this flowsheet were defined in the Eunctional and Operational Requirements ${ }^{(1)}$ (F\&OR) document developed by T.K. Thompson of TKT, Inc. An overall flowsheet from this document is shown in Figure 1. The F\&OR relies on existing and proven technology, and includes processing lines for aqueous liquids, organic liquids, wet solids, homogeneous dry solids, and heterogeneous dry solids. These processing lines are highly integrated. The feedstream definitions are very generic leading to categories of wastes rather than specifying individual components. The broad categories are gas, liquid, and solid. Liquids are further divided into organic and aqueous waste streams. Solids are at times divided into heavy and light combustibles, non-metals (inerts), magnetic metals, and non-magnetic metals. The F\&OR mass balance was performed using an EXCEL spreadsheet by entering assumed splits and conversions. An associated flow'sheet design was prepared by Bechtel using the F\&OR as its basis. The Bechtel Design Study and Cost Estimates ${ }^{(2)}$ contains a more detailed equipment design (but not more detailed feed definitions), as well as sizing and cost information.

A team approach was taken for the modelling of the first flowsheet using ASPEN. The team consisted of John A. Pendergrass and T.K. Thompson of TKT, Inc., representing Los Alamos National Laboratory (LANL); and Laura J. Dietsche and Ravindra S. Upadhye from Lawrence Livermore National Laboratory (LLNL). The first step was to model the F\&OR flowsheet independently at each site, then to compare the models and results. This allowed the team members to become well acquainted with the ASPEN modelling capabilities, and provided a cross-check of our understanding of the processes and underlying assumptions for this basecase flowsheet. The second step was to then combine the best features from both of the site models into a single basecase model. This report focuses on the modelling work conducted at LLNL, however, some comparisons with the LANL model will be made. 


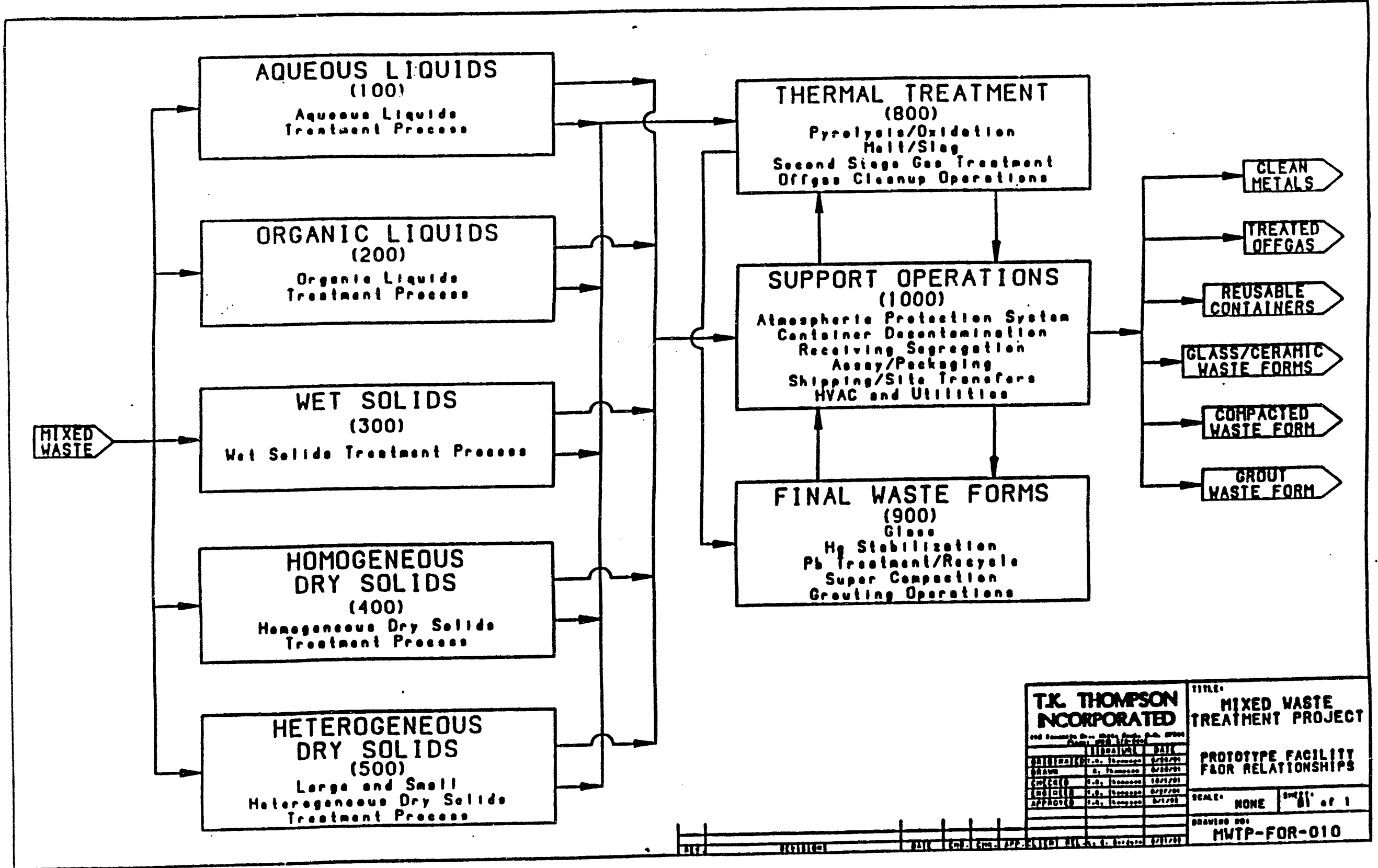

Figure 1: Overall flow diagram for the MWTP basecase taken from the F\&OR(1). 


\section{METHOD:}

Creating an ASPEN model requires a number of steps. The chemical components involved need to be specified and in some cases new components added to the database. For each actual unit operation, the chemical or physical process involved needs to be evaluated, and a suitable ASPEN unit operation model or models chosen. The ASPEN unit models (also called blocks) are then connected, feed stream flows and compositions defined, and operating conditions specified. Control or design specifications can be made using the ASPEN Design-specs (for feed-back control) and FORTRAN statements (for feed-forward control). The thermodynamic models to be used for each block or set of blocks also need to be specified and the appropriate component properties supplied if not already available in the ASPEN database. Design-spec and tear-stream conversion parameters can also be chosen, although ASPEN's default parameters are often appropriate.

One of the goals of the Livermore ASPEN model of the MWTP baseline flowsheet was to model everything in as much detail as possible, making any necessary assumptions. In order to fully utilize ASPEN's thermodynamic capabilities, including fluid phase equilibria calculations, the stream compositions need to be well defined. Unfortunately, most mixed waste streams are not well defined. They include a whole array of radioactive and non-radioactive components and can vary significantly from site to site. This is part of the reason why the MWTP baseline flowsheet and the F\&OR deal with categories of wastes rather than specific components. Therefore, a number of assumptions have gone into the components and feed stream definitions used in the ASPEN model of the MWTP baseline flowsheet. The aqueous portion of the feed streams is defined as water and the liquid organic portion is a cocktail of common organics. The ultimate analyses of the combustibles in the streams entering the incinerators (provided in the F\&OR) were used to estimate the composition of these cocktails (see the ASSUMPTIONS section of this paper). Heavy combustible solids were modeled as wood and light combustibles as paper. Neither of these is in the ASPEN database, so appropriate thermodynamic properties needed to be entered. These combustible solids were first reacted to an ultimate analysis product before being further reacted to a final combustion product using a Gibbs Free Energy minimization reaction.

The combustion products were assumed and included in the component list. Non-metallic solids were modelled as glass $\left(\mathrm{SiO}_{2}\right)$, magnetic metals as $\mathrm{Fe}$, and non-magnetic metals as chrome and $\mathrm{Ni}$. Other components were added as appropriate, such as polyethylene to represent the additive to the polymer final forms, and $\mathrm{CaCO}_{3}$ as the additive to the grout final forms. 
The Livermore model also utilized ASPEN's capability to do electrolyte chemistry when modelling the aqueous streams. This included the reaction of $\mathrm{CO}_{2}$ with water to form carbonic acid (and its associated ions), and the scrubbing of $\mathrm{HCl}$ with both water and $\mathrm{NaOH}$. The formation of solid $\mathrm{NaCl}$ was also considered. The downside of going to this level of detail is dealing with more difficult convergences and longer simulation times.

Converting the F\&OR flowsheet operational blocks into an ASPEN model required breaking down the blocks into more fundamental unit operations. The Bechtel Study was often used to provide details missing in the F\&OR. The method was essentially the same for each operational block. One example of a conversion of an F\&OR block to an ASPEN model is the "Offgas Treatment" block found on the F\&OR Thermal Treatment flowsheet shown in Figure 2. The flowrates in and out are provided in the Stream Table. The F\&OR text provides additional information as to what operations are typically involved in the further treatment of offgas, but does not give any details as to how this equipment is piped together nor does it supply any operation specifications. The Bechtel report provides a possible piping scheme as well as some temperature, heat, and flowrate specs as seen in Figure 3. Information from both of these reports was used to create the ASPEN flowsheet shown in Figure 4. The offgases from the secondary combustion chamber, the final forms mixers and the solids melters are first sent through a quench column, then through a venturi scrubber, and finally through an aqueous absorber column. "Fresh" water (recycled from the aqueous treatment system) is fed to the absorber column, and the absorber bottoms steam is then used as the quench column makeup water, the aqueous purge from the quench column is then sent to the venturi scrubber and finally back to the aqueous treatment system. The quench column was modelled as a simple FLASH2 (two-phase flash) block, where the heat from the incoming gasses is transferred to the cooling water. A certain amount of the solids are assumed to be entrained in the vapor outlet stream. The temperature of the quench outlet streams and the cold recycled water stream were taken from the Bechtel report. The amount of recycled water is determined by a design specification (or design-spec) which makes the quench column adiabatic; i.e. the actual heat removal occurs in the quench recycle stream heat exchanger. The venturi scrubber is also modelled as a FLASH2 unit to remove most of the remaining solids from the vapor stream. ASPEN has a more detailed venturi model available, but it requires information about the particle size distribution of the solids which was not readily available. This is one of the many refinements which could eventually be made to this model. The solids are filtered out of the aqueous outlet stream from the venturi with a SEP (component separation) block and 


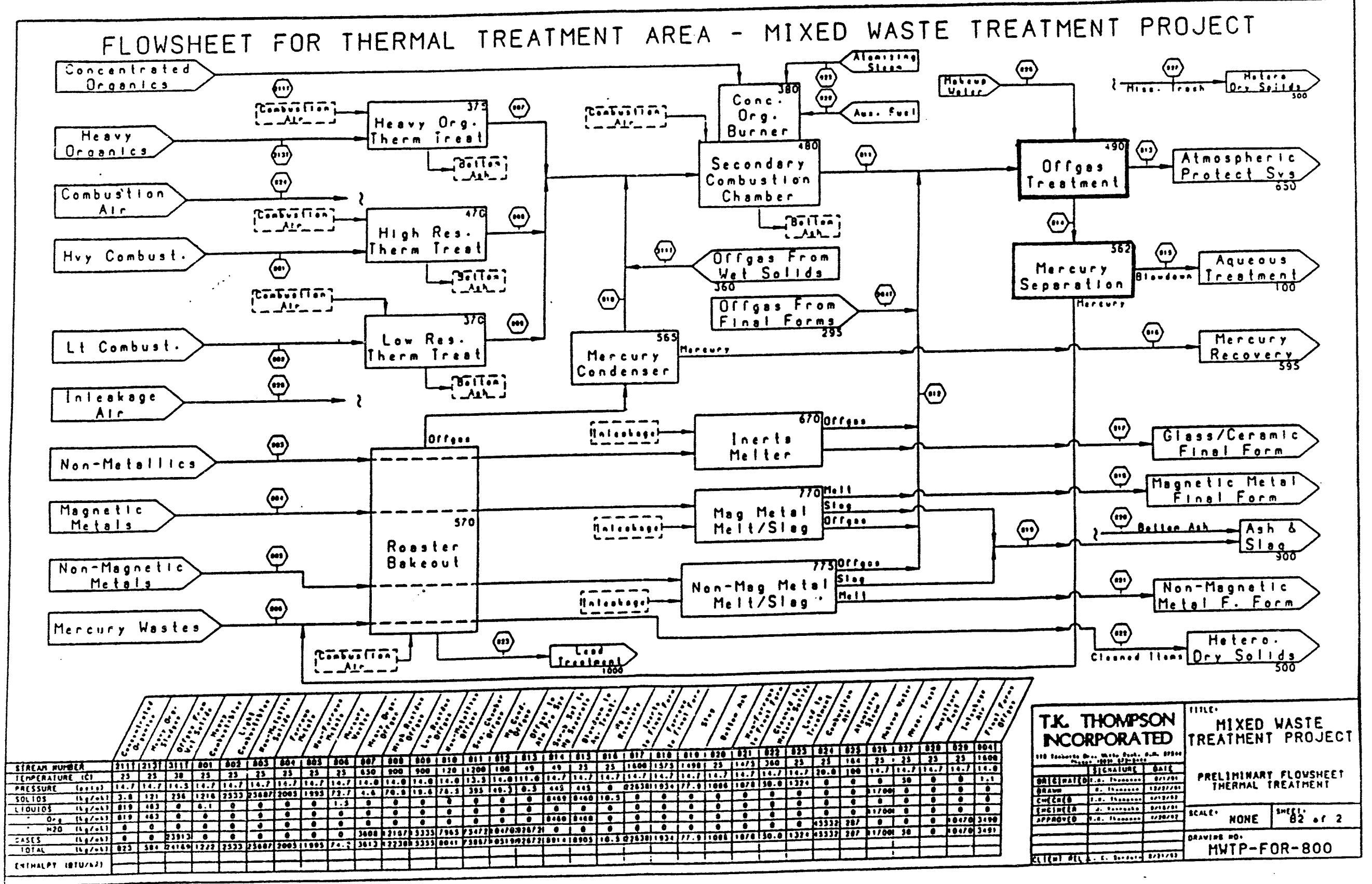

Figure 2: Thermal treatment and offgas treatment flowsheet for the MWTP basecase taken from the F\&OR(1). 


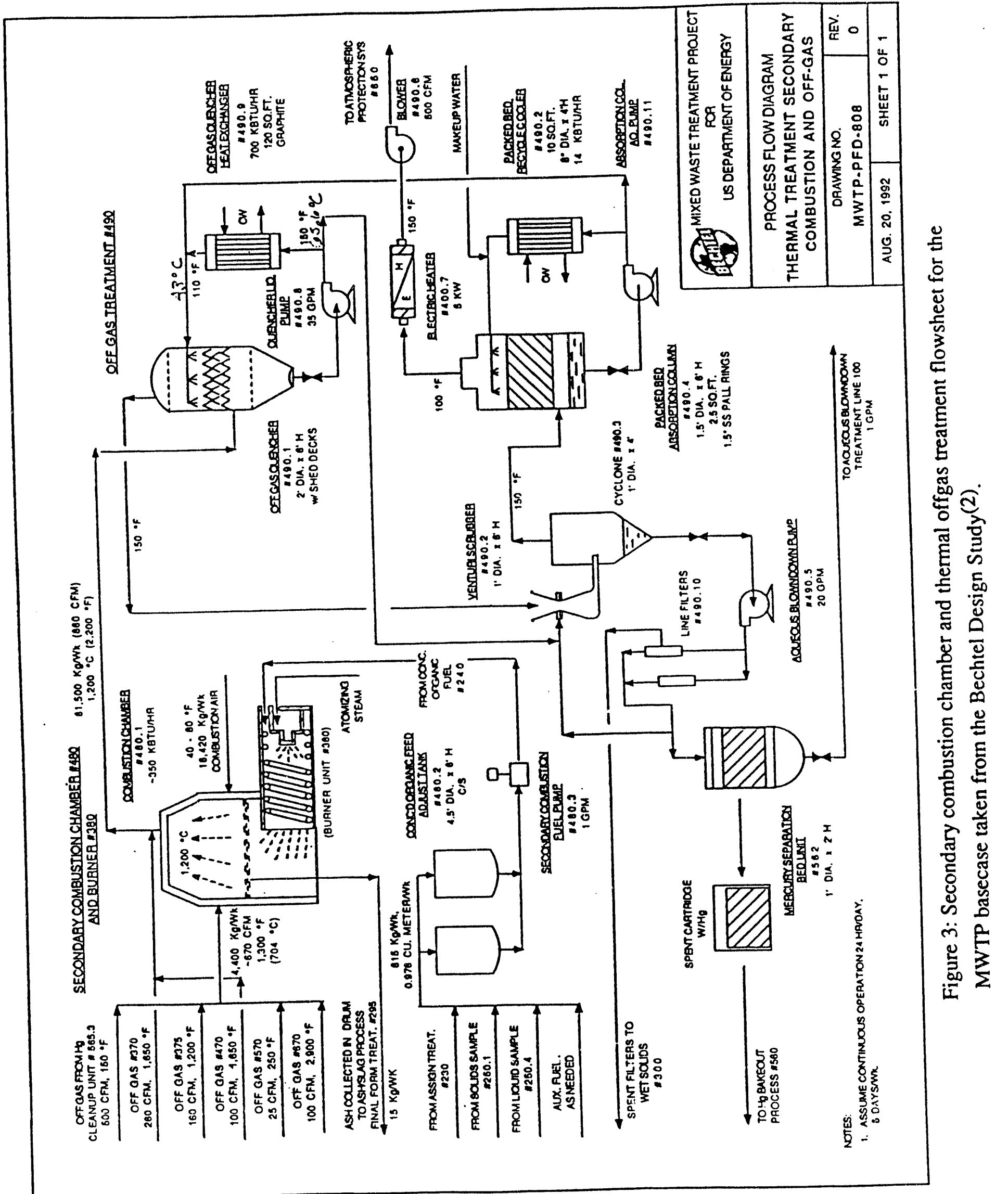




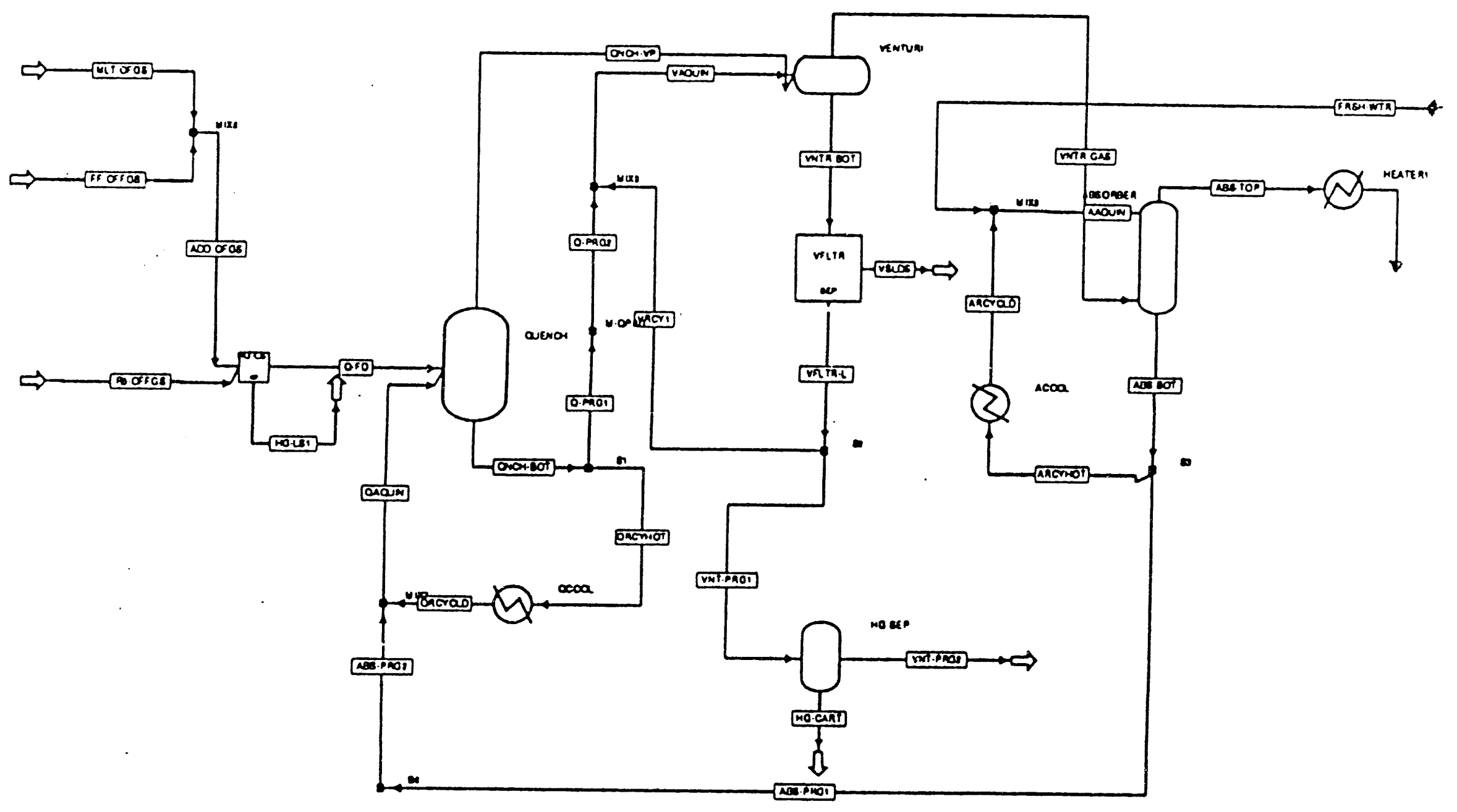

Figure 4: Thermal offgas treatment flowsheet for the MWTP basecase, from the LLNL ASPEN model. 
part of the stream is recycled back to the venturi. The amount of recycle is again determined by a design spec to obtain a typical venturi water to gas ratio. The absorber is modelled by a RADFRAC (rigorous multi-stage distillation column) block with no reboiler or condenser. The number of stages is only estimated at this point and could be refined later. The recycle stream around the absorber column is held constant at a rate estimated from the pump capacity in the Bechtel report. The amount of "Fresh" water added to the absorber is determined from a design spec to control the amount of $\mathrm{HCl}$ in the final offgas. A number of process specifications which were not available in either the F\&OR or the Bechtel reports had to be estimated.

The ASPEN model was initially created in sections which were then hooked together to form the overall MWTP basecase model. Flowsheets for the individual sections are shown in Figures 5 through 11. The organic feed preparation blocks formed one section, and the organic incinerators a second section. The offgas treatment system for both the thermal offgas and the offgas going to the final atmospheric protection system made up a third section. These three sections were initially hooked together and modified to obtain convergence. The aqueous feed treatment system was created next and then added on. Two different versions of the aqueous flowsheet were created. One uses the secondary polishing method suggested in the F\&OR, ion exchange. The other one uses an evaporator for secondary polishing as indicated in the Bechtel Design Study. The over all flowsheet contains the ion exchange version for now. The fifth section to be modelled combined the solids thermal treatment and final forms processing equipment. The sixth and final section for the ASPEN model included equipment for the drying of the wet solids.

A few of the connecting tear (recycle) streams between sections and one of the recycle streams within the offgas treatment section were left unconnected during most of the development to avoid convergence problems and long (e.g., 24 hour) simulation times. These included the streams going from the wet solids drying section to both the aqueous processing section and to the incinerator, the final atmospheric protection system's scrubber bottoms stream which was recycled back to the aqueous treatment section, and the purge stream from the thermal offgas absorber which became makeup to the quench column. Feed streams were created which approximated the composition and flowrate of the connccting stream.

The modelling approach taken at LANL was somewhat different providing a good test for comparison. The LANL approach was to start at a low level of detail using the split assumptions given in the F\&OR, then to increase the complexity as more detailed information was made available. Information from the Bechtel Design Study 


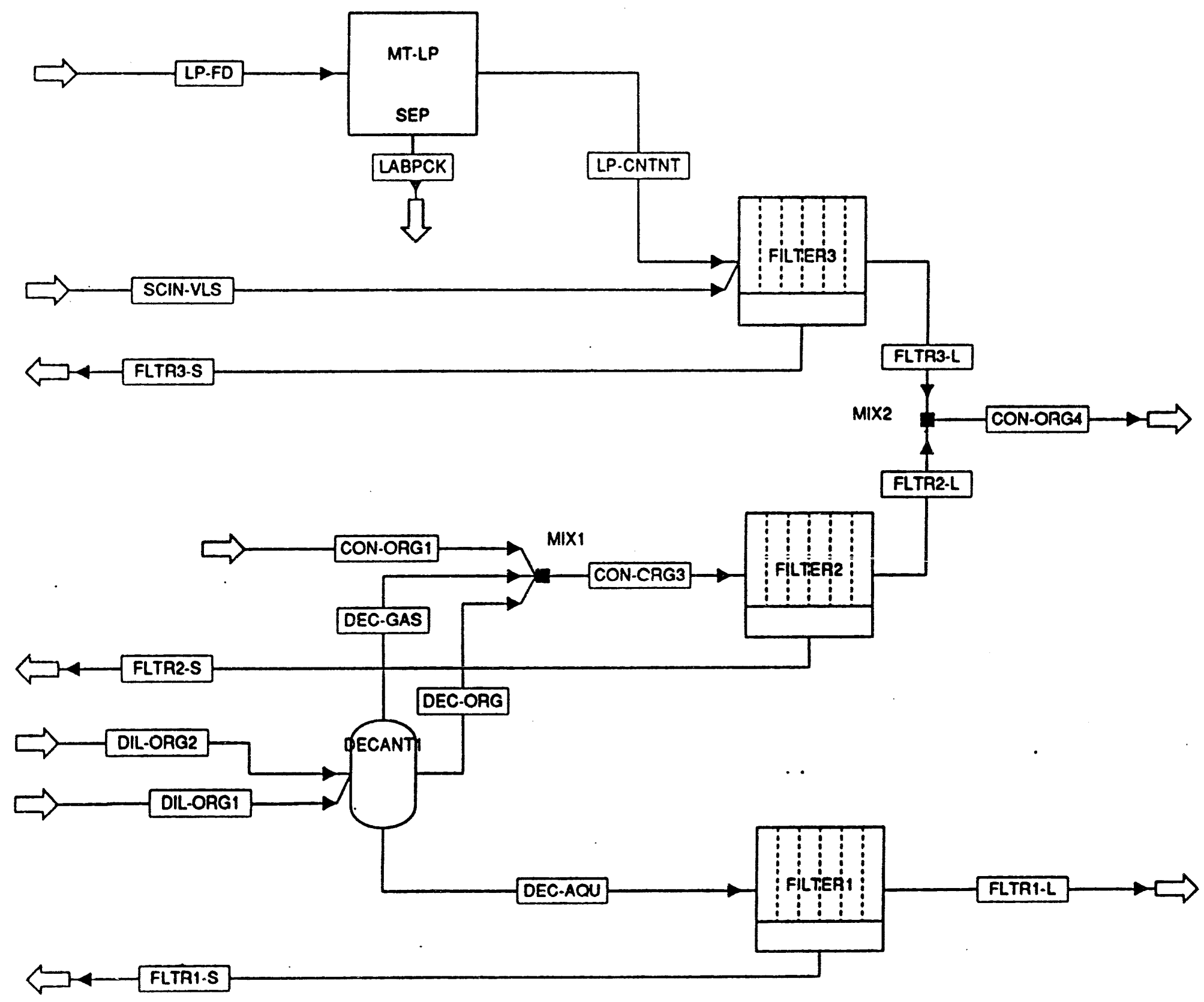

Figure 5: Organic feed preparation flowsheet for the MWTP basecase, from the LLNL ASPEN model. 


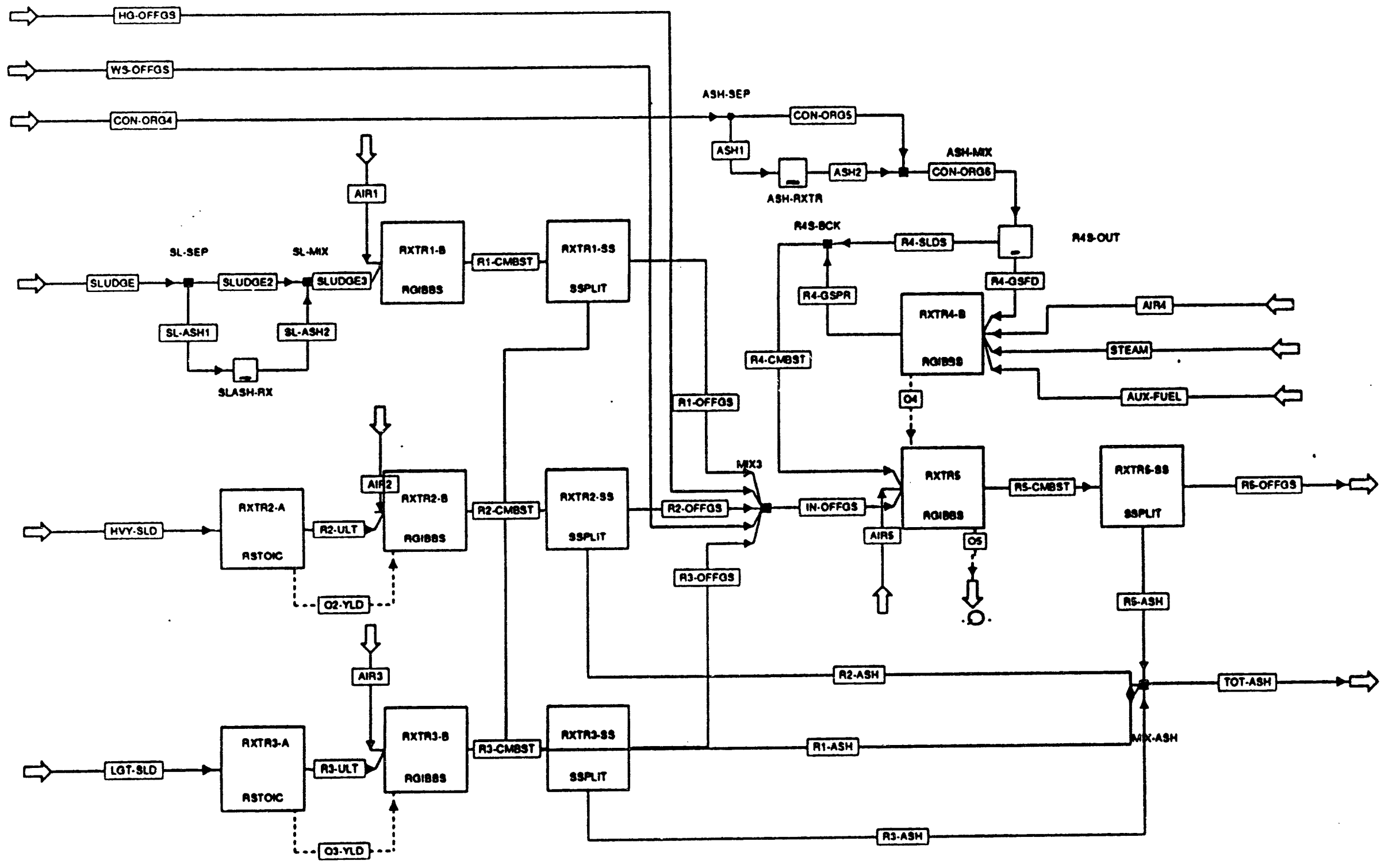

Figure 6: Organic thermal processing flowsheet for the MWTP basecase, from the LLNL ASPEN model. 


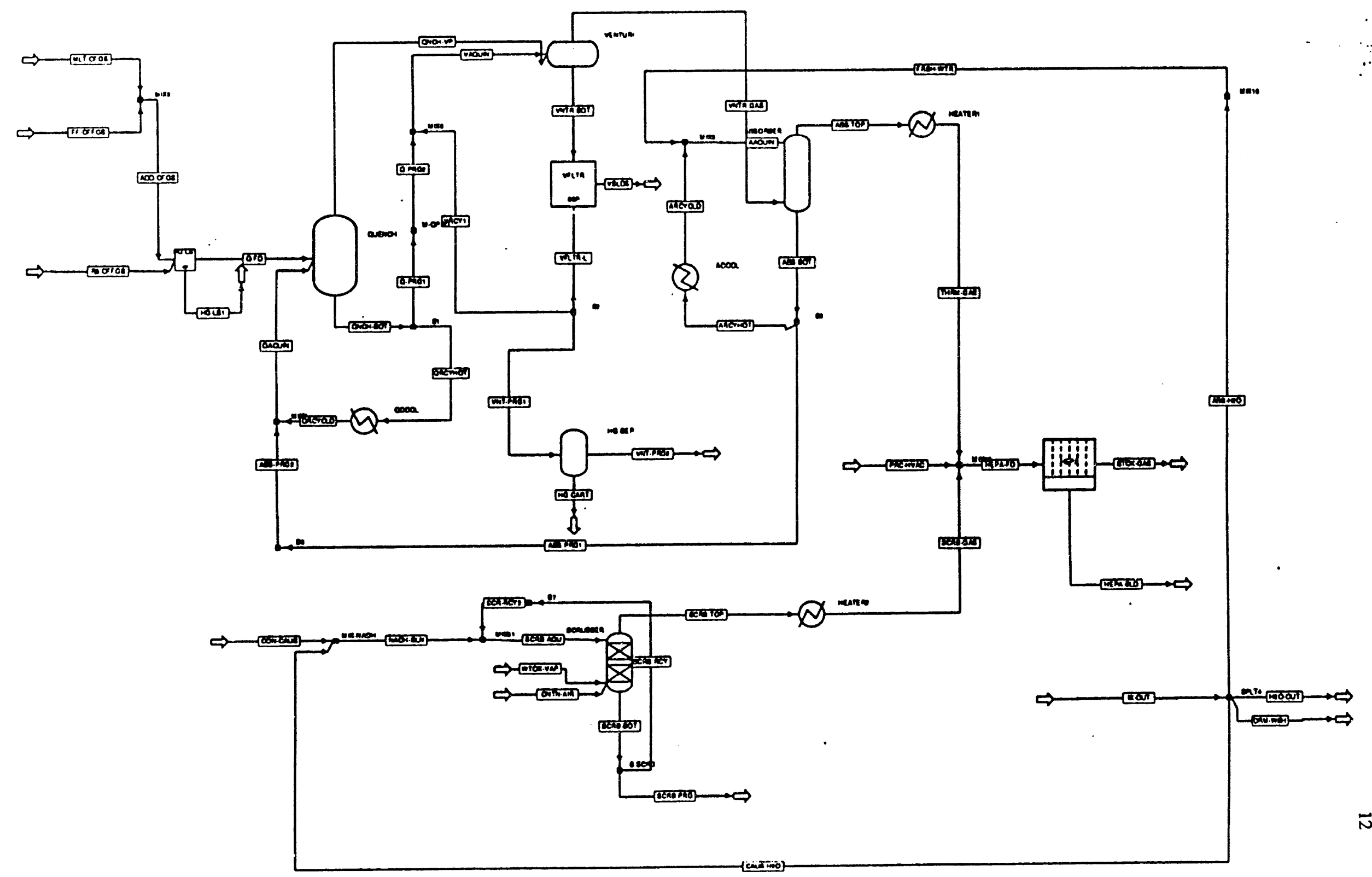

Figure 7: Thermal and system offgas treatment flowsheet for the MWTP basecase, from the LLNL ASPEN model. 


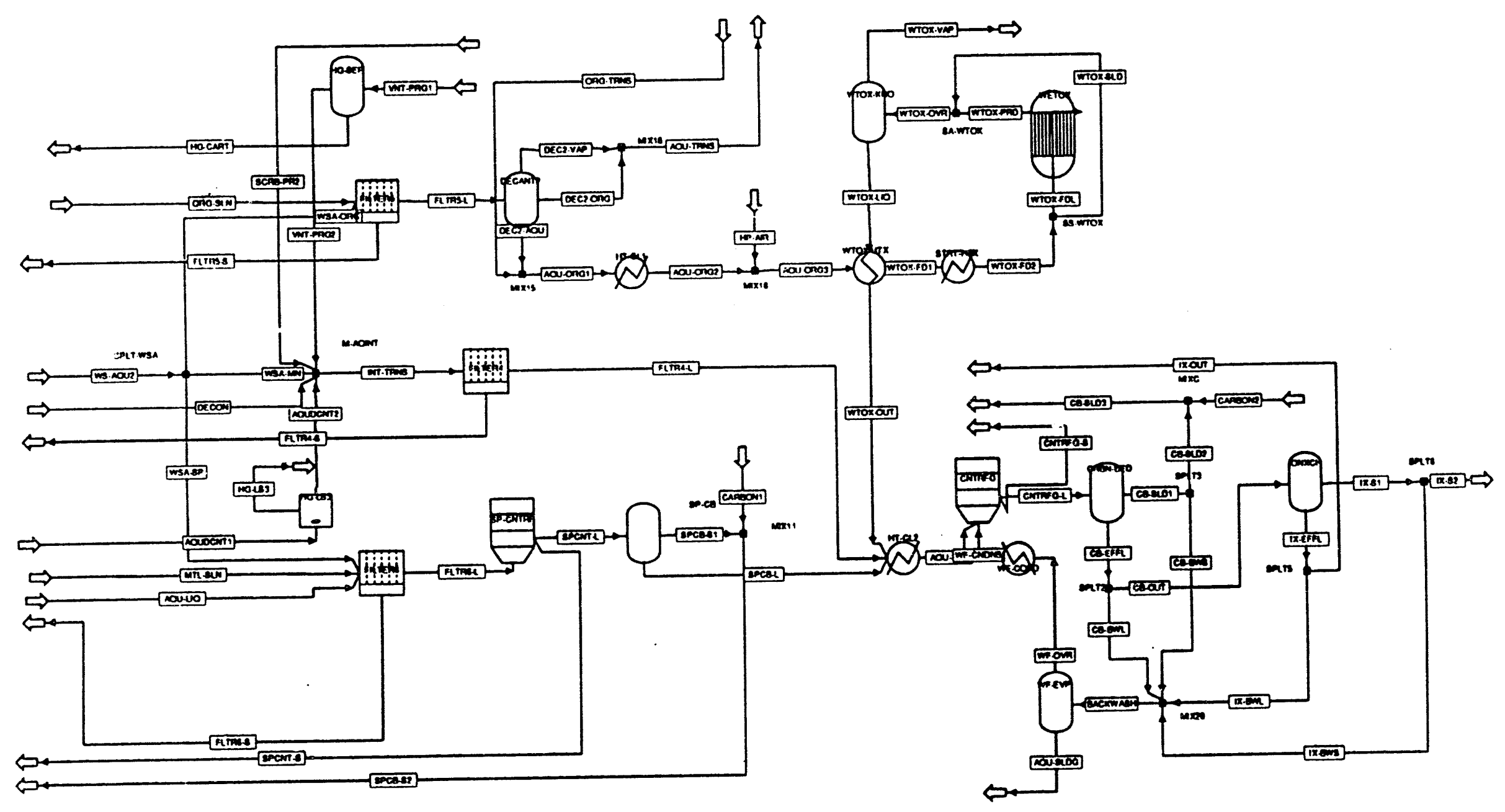

Figure 8: Aqueous feed treatment flowsheet for the MWTP basecase, from the LLNL

ASPEN model - version 1: includes an ion exchange column as the secondary polishing unit. 


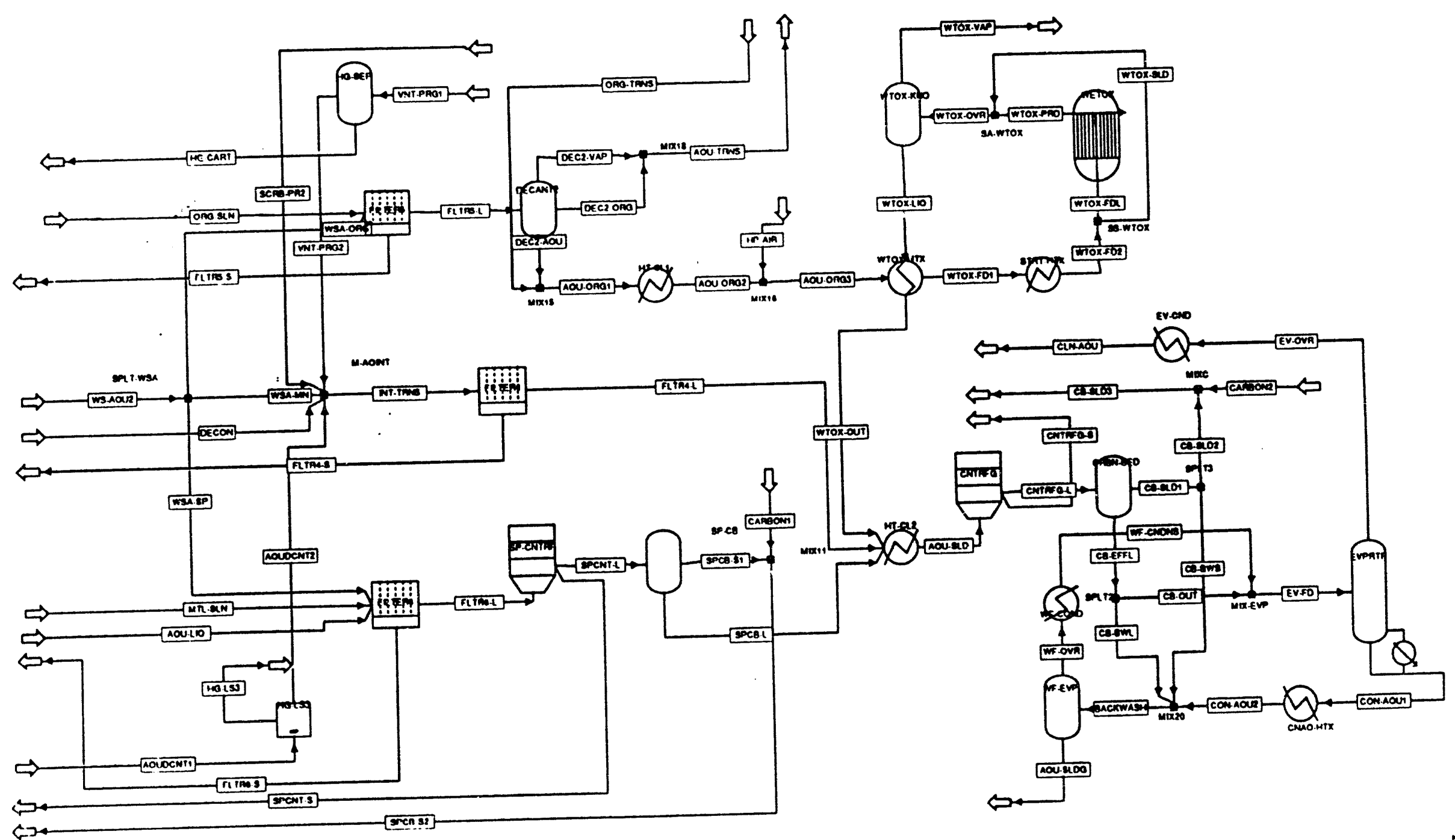

Figure 9: Aqueous feed treatment flowsheet for the MWTP basecase, from the LLNL ASPEN model - version 2: includes an evaporator as the secondary polishing unit. 


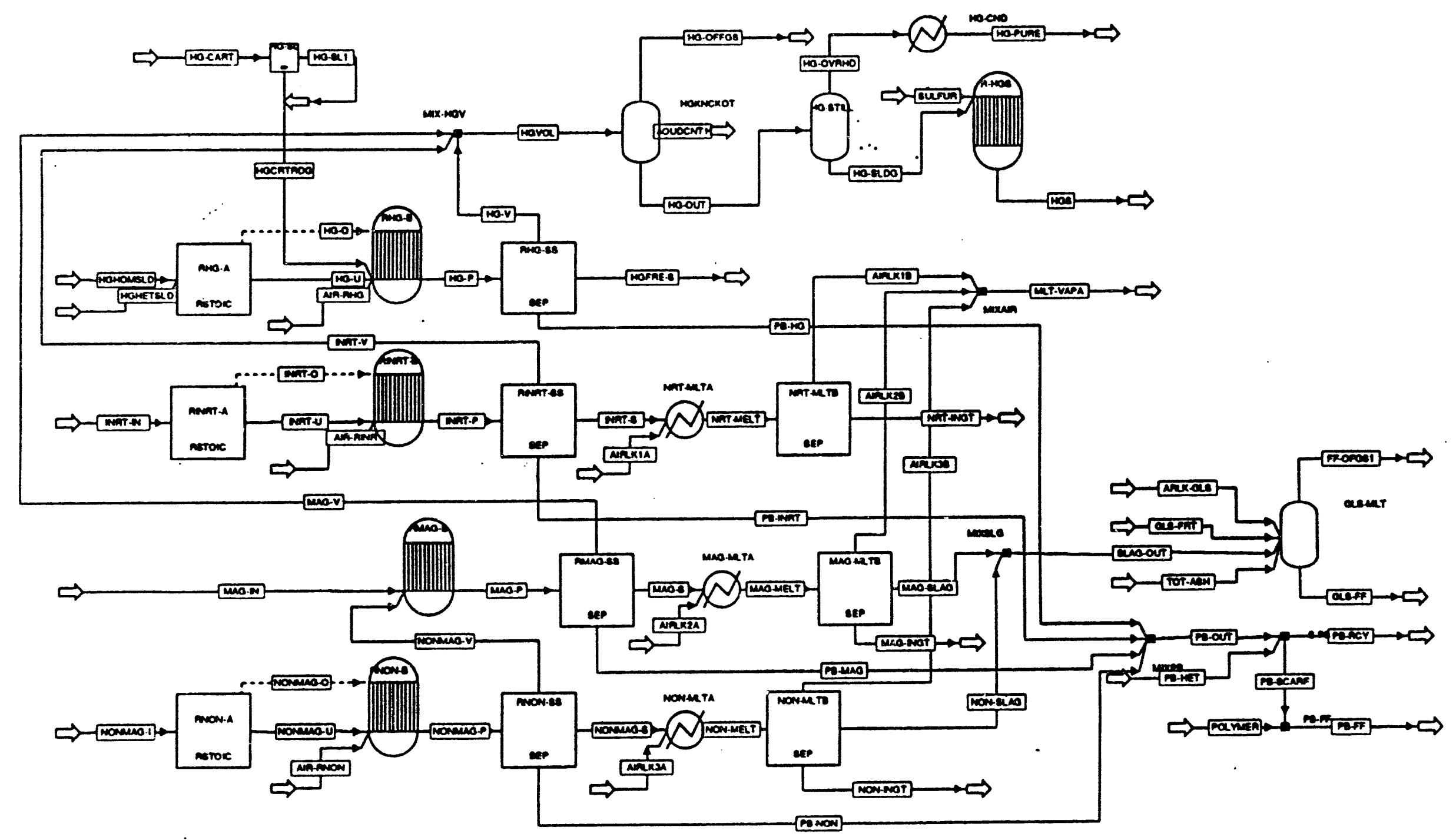

Figure 10: Non-organic solids thermal treatment and final forms flowsheet for the MWTP basecase, from the LLNL ASPEN model. 


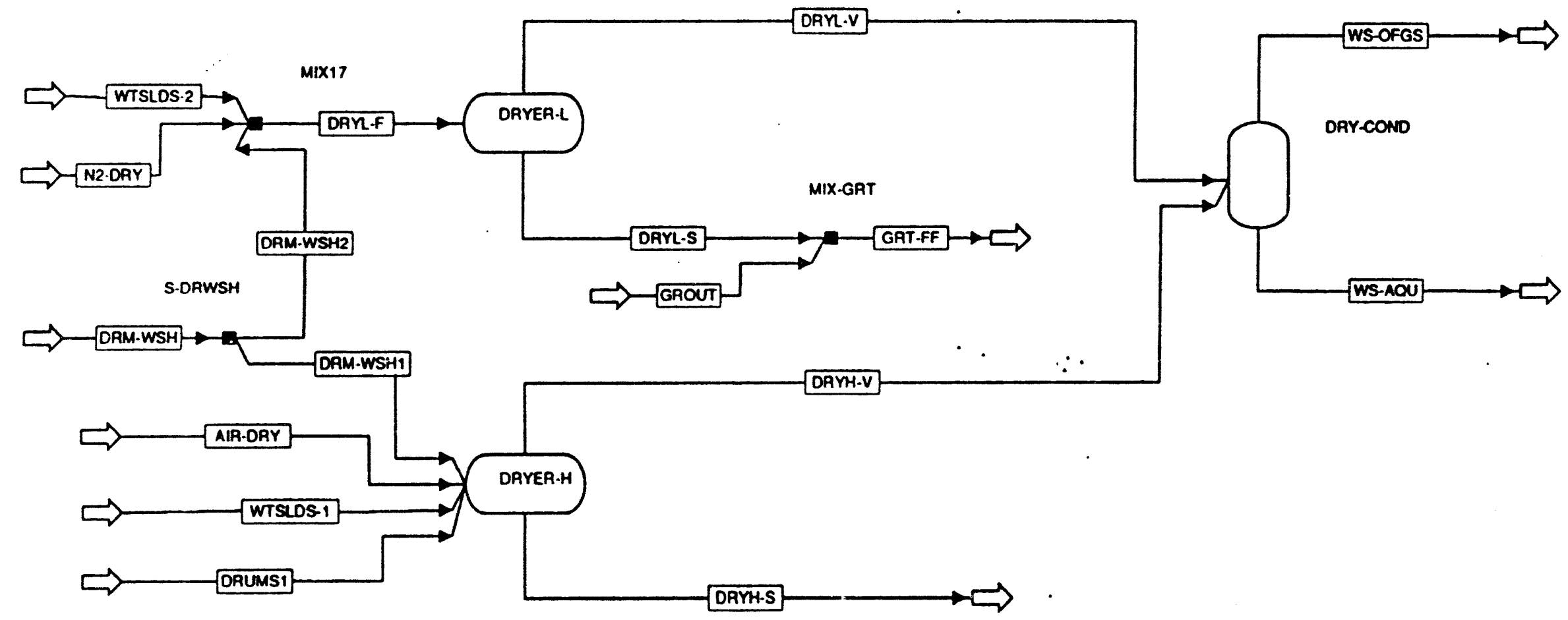

Figure 11: Wet solids drying flowsheet for the MWTP basecase, from the LLNL ASPEN model. 
was not utilized. The LANL model includes extensive front end solids sorting, and utilizes mostly "hlack box" separators with assumed separations. The LANL model utilized a built-in estimation package in ASPEN based on thermodynamic coal models to determine the properties of the combustibles based on their ultimate analyses. These combustibles are first converted to an ultimate analysis product before being further reacted to the final combustion products using a Gibbs Free Energy minimization reaction. A comparison of the results form the LANL and LLNL models will be made in the results section of this report.

\section{ASSUMPTIONS}

The MWTP baseline flowsheet is still in a preliminary design stage requiring numerous assumptions to be made when defining feeds and determining the specs in the ASPEN model. Most of the assumptions are based on information contained in the F\&OR or Bechtel Design Study reports, but many of the assumptions are based on "engineering judgement" or intuition. The ASPEN input file located in Appendix A contains numerous comment statements which specify most of the assumptions made. They will not all be repeated here. Assumptions which required significant leaps from the F\&OR or extensive calculations are outlined below.

The F\&OR states flowrates on a per week basis (using a $60 \%$ on-stream factor) to allow flexibility in operation scheduling. The ASPEN model has been converted to an hourly bases assuming a $168 \mathrm{hr} / \mathrm{wk}$ ( $24 \mathrm{hr} /$ day, 7 day/wk) operating schedule. This can be easily modified by placing an ASPEN multiplier block in each of the feed streams using the same multiplication factor, or by using the report scaling option to scale all of the streams in the report to a specified stream and flowrate.

This brings up an important point about ASPEN modelling in general. ASPEN is a continuous process modelling program. It does not model batch processes except for batch reactors (given reaction rate data) with surge tanks on either side connecting it to continuous equipment. Due to the small size of many of the mixed waste streams, some of the mixed waste treatment units may be run either batch or in a "batch-continuous" (campaigned) mode. The batch-continuous equipment can be modelled by running different cases with the campaigned flows either "on" or "off". The truly batch equipment cannot be modelled in detail using ASPEN. As a case in point, the sludge (or heavy organics) incinerator is specified to be run batchwise with a slowly increasing temperature profile and a changing air flowrate. This will volatilize and oxidize the organics first in increasing molecular weight, then oxidize the steel drums at a higher 
temperature. The ASPEN model treats this as a continuous process using an average temperature given in the Stream Table on the F\&OR flowsheet.

As previously mentioned, the liquid organic stream compositions were based on the ultimate analysis information given in the F\&OR for the combustibie portion of the incinerator feed streams. Nitrogen was obtained from acetonitrile $\left(\mathrm{C}_{2} \mathrm{H}_{3} \mathrm{~N}\right)$, sulfur from methyl mercaptan $\left(\mathrm{CH}_{4} \mathrm{~S}\right)$, and chlorine from carbontetrachloride $\left(\mathrm{CCl}_{4}\right)$. ()xygen came from ethanol $\left(\mathrm{C}_{2} \mathrm{H}_{6} \mathrm{O}\right)$, methylethylketone $\left(\mathrm{C}_{4} \mathrm{H}_{8} \mathrm{O}\right)$, or glycerol $\left(\mathrm{C}_{3} \mathrm{H}_{8} \mathrm{O}_{3}\right)$. Benzene $\left(\mathrm{C}_{6} \mathrm{H}_{6}\right)$ and $\mathrm{N}$-octane $\left(\mathrm{C}_{8} \mathrm{H}_{18}\right)$ were used to complete the carbon and hydrogen balances.

For the sludge feed stream (F\&OR stream $\# 213$, Heavy Organics) this was a fairly straight forward exercise. In this case, glycerol was used to supply the oxygen in an attempt to create a more viscous (supposedly unpumpable) stream, but the resulting cocktail was not extremely viscous. $\mathrm{SiO}_{2}$ was added to the organics to represent the solid inerts, and $0.5 \%$ of the total mass was specified to be mercury. Iron and chrome were added to represent the drums which were incinerated along with their contents.

For the liquid organic stream entering RXTR4B, the concentrated organics burner, (F\&OR stream \#211, Concentrated Organics) the creation of the appropriate organic cocktail was a little more involved since this stream is a combination of a number of other streams coming from filters and decanters, including recycle streams from other sections of the flowsheet. In this case the desired composition of the burner feed cocktail could be determined, and estimates of the contributing feed stream organic compositions made to obtain this cocktail, while maintaining the organic flowrates of the contributing streams found in the F\&OR. A number of iterations and modifications were required to get close to the desired final cocktail composition.

One stream which contributed to the organic burner stream, the labpack and scintillation vial streams (F\&OR \#202, Concentrated Organics to Solids Separator), required extra assumptions due to some missing information in the F\&OR. Apparently, the flows reported in the Stream Table did not account for the labpacks, absorbents, vials, etc., resulting in a low solids phase flowrate. In this case, the Livermore ASPEN model assumes that the liquid organic flowrate given in the F\&OR Stream Table is correct as $240 \mathrm{~kg} / \mathrm{wk}$. (The LANL model assumes that the total flowrate is correct. This difference will be pointed out later when comparing results.) The labpack waste stream was specified in the F\&OR to be $3.5 \mathrm{wt} . \%$ of the total drummed organics, giving a labpack stream net weight of $49.4 \mathrm{~kg} / \mathrm{wk}$. From a surrogate waste stream definition given in a Mixed Waste Integrated Program (MWIP) document $(3)$, the labpack contents were assumed to be $60 \mathrm{wt} . \%$ organics, $20 \%$ bottles, $16 \%$ absorbent, and $4 \%$ other solids (e.g., lead, chrome, iron, mercury). Assume that the labpacks themselves are $10 \%$ of the total 
labpack stream weight. This allows us to determine the labpack stream composition. The remaining organics in F\&OR stream \#202 are assumed to be contained in the scintillation vial stream. The F\&OR specifies that the scintillation vial drums are $75 \%$ full by volume (total drum volume is $0.208 \mathrm{~m}^{3}$ ) with a net weight of $125 \mathrm{~kg} / \mathrm{drum}$. The occupied volume is $50 \%$ vials and $50 \%$ liquid (assumed to contain $5 \%$ dissolved or suspended solids with an overall density of $0.9 \mathrm{gm} / \mathrm{ml}$ ). These assumptions allow us to determine a scintillation vial stream composition.

The F\&OR stated oxygen requirements for the incinerators in terms of percent of that required for total combustion. These requirements were translated as design specification in the ASPEN model. When a specification of $100 \%$ of stoichiometric air was made, the design-spec was set up to adjust the incoming air so that the flow of $\mathrm{O}_{2}$ out equaled 0.01 of that entering the incinerator. (This allows for $102 \%$ of stoichiometric air, since $100 \%$ would result in no $\mathrm{O}_{2}$ exiting, which would be satisfied by any amount of air less than or equal to the stoichiometric amount.) When $200 \%$ of stoichiometric air was specified, the design-spec required that the flow of $\mathrm{O}_{2}$ exiting the incinerator be half of that entering. The design-spec became a little more complicated when $50 \%$ of stoichiometric air was required. In this case we would expect to see essentially no oxygen in the exiting gas stream, but we would expect substantial amounts of $\mathrm{CO}$ and only a small amount of $\mathrm{CO}_{2}$. (Assume that the air is somewhat over the $50 \% \mathrm{spec}$ to assure the presence of some $\mathrm{CO}_{2}$.) Assume that a majority of the oxygen is being used to oxidize carbon and hydrogen. (This will of course depend of the composition of the organics being oxidized, but for the ultimate analyses provided in the F\&OR, this should be the case.) The carbon reaction can be represented by

$$
\mathrm{nC}+\mathrm{fnO}_{2} \rightarrow \mathrm{xCO}_{2}+(\mathrm{n}-\mathrm{x}) \mathrm{CO}
$$

where $f$ is the fraction of oxygen that would be needed for the complete combustion of carbon to carbondioxide which is being consumed by this reaction. An oxygen atom balance for this reaction gives us

$$
x+(n-x) / 2=f n
$$

Similarly for hydrogen we have

$$
\mathrm{mH}_{2}+\mathrm{gm} / 2 \mathrm{O}_{2}=\mathrm{gmH}_{2} \mathrm{O}+(\mathrm{m}-\mathrm{gm}) \mathrm{H}_{2}
$$


where $\mathrm{g}$ is the fraction of oxygen that would be needed for the complete combustion of hydrogen to water which is being consumed by this second reaction. The oxygen atom balance for this reaction does not provide any new information. The total oxygen consumption can be represented by

$$
f n+g m / 2=F(n+m / 2)
$$

where $\mathrm{F}$ is the fraction of oxygen that would be needed for the total combustion of both carbon and hydrogen which is being consumed by both reactions. Equations (1) and (2) can be combined and rearranged to give

$$
x=(2 F-1)(n-x) /[2(F-1)]+F(m-g m) /[2(F-1)]-g m / 2
$$

From the reactions above it can be seen that $x$ will equal the $\mathrm{CO}_{2}$ concentration in the incinerator offgas, ( $n-x)$ will equal the $\mathrm{CO}$ concentration, (m-gm) the $\mathrm{H}_{2}$ concentration, and $\mathrm{gm}$ the $\mathrm{H}_{2} \mathrm{O}$ concentration. When F equals .55 ( $55 \%$ of stoichiometric air required) we obtain the design spec equation

$$
\left[\mathrm{CO}_{2}\right]=0.11[\mathrm{CO}]+0.61\left[\mathrm{H}_{2}\right]+0.5\left[\mathrm{H}_{2} \mathrm{O}\right]
$$

This equation was used for the sludge (heavy organics) incineration in RXTR1. Although not exact, it should provide an amount of air close to that desired.

The electrolyte thermodynamic package uses Henry's Law to determine the vapor composition in equilibrium with the aqueous liquid. When soluble or entrained organics are present in the aqueous stream (even in very minute amounts), Henry's Law constants must be provided for these organics in order to perform VLE calculations. Since most of these organics are not very soluble in water, it is very difficult (or impossible) to find values for the Henry's Law constants (or the associated VLE data) in the open literature. In order to provide some data, we assumed that the water would not have a strong influence on the organics and therefore that the mole fraction of the organics in the vapor would equal that in the liquid; i.e., we assumed that the Henry's Law constant was equal to the vapor pressure of the organics. ASPEN requires that the Henry's Law constant, $H$, be given in the form, $\ln H=a+b / T+\operatorname{cn} T+d T$, where $T$ is the absolute temperature and $a, b, c$, and $d$ are empirical constants. We assumed that $c$ and $d$ were equal to zero and determined the values of $a$ and $b$ to correlate with vapor pressure data 
found in the Handbook of Chemistry and Physics $\left({ }^{(4)}\right.$. The results are given in Table1. This approach will most likely be in error for highly soluble organics. For the organics we are using, the most soluble are ethanol and MEK. Solubility and VLE data on ethanol $(5)$ is shown in Table 2 along with the calculated Henry's Law constants as a function of temperature. It can be seen that the mole fractions of ethanol in the liquid and vapor phases are very close as was assumed in using the vapor pressure approach to evaluating the Henry's Law constant. Indeed the values of the correlation constants a and $\mathrm{b}$ are very close for the two approaches. This is very encouraging. However, VLE data for MEK in water ${ }^{(6)}$ given in Table 3 shows an order of magnitude difference in the liquid and vapor phase mole fractions of MEK due to hydrogen bonding in the liquid phase. There is not enough data to do an accurate regression on $a$ and $b$ from this data, but it could be significantly different from the values determined from the vapor pressure data. For lack of any better VLE data on MEK, we will continue to use the vapor pressure approach for now.

The electrolyte calculation package seemed to have real trouble handling liquid mercury in the aqueous stream. Therefore the mercury in streams entering an aqueous section of the flowsheet (Aqueous Treatment, Offgas Treatment, and Wet Solids Drying) was first moved to the conventional solids phase or substream and thereafter treated as a solid. This seems at least somewhat reasonable since mercury should sink to the bottom of any aqueous stream, although the possibility of reactions to form soluble salts containing mercury (such as mercuric chloride) should be considered in future models. When mercury vapor-liquid or liquid-liquid equilibrium calculations were required (in the non-aqueous section of the flowsheet), the mercury was moved back to the "mixed" substream.

One of the systems which differed for the F\&OR and the Bechtel Design Study was the mercury removal and clean-up system. In both cases, the aqueous letdown from the thermal offgas treatment system passes through a mercury separation unit before being recycled to the aqueous treatment section. The spent cartridges contaminated with mercury are sent, along with any solid inert or metallic wastes known to contain mercury, to a mercury bakeout furnace. The offgases from this furnace go through a condenser and knockout pot to condense out the mercury. The F\&OR condenser operates at $120^{\circ} \mathrm{C}$, allowing water and some mercury vapor to return to the secondary combustion chamber and offgas treatment system. The condensed mercury is distilled to recover a reusable mercury stream overhead. The still bottoms are reacted with sulfur to produce cinnabar which is then encapsulated into a final form. The Bechtel process operates the 
Table 1: Assumed Henry's law empirical constants, $a$ and $b$, for various organics. The Henry's law equation is $\ln H=a+(b / T)$, where $H$ is in atmospheres and $T$ in degrees Kelvin. The correlation assumes that the Henry's law constant, $H$, approximately equals the pure component vapor pressure.

\begin{tabular}{lccc}
\multicolumn{1}{c}{ ORGANIC } & $\mathbf{a}$ & $\mathbf{b}$ & $\mathbf{r}^{2}$ \\
\hline carbontetrachloride & 10.61 & -3738.8 & -0.9996 \\
octane & 11.33 & -4541.7 & 0.9995 \\
dodecane & 12.70 & -6187.8 & -0.9999 \\
methyl mercaptan & 10.52 & -2938.4 & -0.9999 \\
acetonitrile & 11.14 & -3953.5 & -1.0000 \\
benzene & 10.85 & -3849.2 & -0.9997 \\
ethanol & 13.52 & -4779.5 & -0.9995 \\
MEK & 11.17 & -3936.7 & -1.0000
\end{tabular}

* Statistical fit to the vapor pressure data found in reference 4.

Table 2: VLE data ${ }^{(5)}$ and the corresponding Henry's law constants for ethanol in water. The empirical constants for the Henry's law equation, $\ln H=a+(b / T)$, are also given, where $H$ is in atmospheres and $\mathrm{T}$ is in degrees Kelvin.

\begin{tabular}{ccccc}
$\mathbf{T}, \mathbf{K}$ & $\mathbf{x}$ & $\mathbf{y}$ & $\mathbf{P}, \mathbf{k P a}$ & $\mathbf{H}=\mathbf{y p} / \mathbf{x}, \mathbf{a t m}$ \\
\hline 303.15 & 0.05 & 0.478 & 10.46 & 0.1 \\
323.15 & 0.05 & 0.505 & 29.53 & 0.3 \\
343.15 & 0.05 & 0.522 & 72.53 & 0.8 \\
363.15 & 0.05 & 0.531 & 158.65 & 1.7
\end{tabular}

$\mathrm{a}=14.86, \mathrm{~b}=-5198.4, \mathrm{r}^{2}=-0.9999$

Table 3: VLE data and the corresponding Henry's law constants for MEK in water.

\begin{tabular}{ccccc}
$\mathbf{T}, \mathbf{K}$ & $\mathbf{x}$ & $\mathbf{y}$ & $\mathbf{P}, \mathbf{k P a}$ & $\mathbf{H}=\mathbf{y p} / \mathbf{x}, \mathbf{a t m}$ \\
\hline 98.84 & 0.00175 & 0.0427 & 101.325 & 24.72 \\
99.65 & 0.00100 & 0.0142 & 101.325 & 14.39
\end{tabular}


condenser at $10^{\circ} \mathrm{C}$, removing most of the water and mercury from the offgas stream. The water forms a liquid layer on top of the mercury and is decanted and sent to the aqueous treatment section. If the mercury layer is pure enough, it is recycled as is, otherwise it is further distilled, with the bottoms reacted to cinnabar (without further encapsulation). The offgas from the condenser is sent through a Boliden/Norzink processing system to remove any remaining mercury before going to the secondary combustion chamber. This patented process involves scrubbing the offgas with a mercuric chloride $\left(\mathrm{HgCl}_{2}\right)$ solution to form mercurous chloride $\left(\mathrm{Hg}_{2} \mathrm{Cl}_{2}\right)$ which precipitates out. Part of the mercurous chloride is treated with chlorine to form more mercuric chloride which is then recycled back to the scrubber. The rest is removed as a sludge. In comparing the F\&OR and the Bechtel flowsheets for mercury handling, the ASPEN modelling team felt that purification of the condenser offgas using the Boliden/Norzink process was not warranted since mercury is also contained in other feed streams to the secondary combustion chamber. However, this process might be useful as a first step in the thermal offgas treatment system. The current LLNL ASPEN model uses the F\&OR system except that the condenser temperature has been lowered to $10^{\circ} \mathrm{C}$ to remove more mercury (and water) from the offgas stream.

In order to model the Boliden/Norzink process using ASPEN, more processing information is required than that provided in the Bechtel Design Study. To this end a literature search on the process was performed. The results of this search will be provided here in order to enable the Boliden/Norzink process to be included in future MWTP ASPEN models. The patents involved are found in references 7 to 9 . An article on the process development can be found in reference 10, and one describing application of the process in reference 11. Properties of mercuric and mercurous chloride can be found in references 12 to 14 . Since the reactions occur in aqueous solutions, the ASPEN electrolyte package should probably be utilized to model this process.

Another difference between the F\&OR and the Bechtel Design Study is the composition of the aqueous stream going to the final atmospheric protection system scrubber. The F\&OR uses pure water, while the Bechtel report uses a $10 \%$ caustic $(\mathrm{NaOH})$ solution. The LLNL ASPEN model uses the Bechtel approach for this system. The amount of caustic added is adjusted so that $30 \%$ of the caustic is consumed in scrubbing the acids in the offgas. 


\section{RESULTS AND OBSERVATIONS}

The input and report files from the Livermore ASPEN model of the MWTP baseline flowsheet are given in Appendices A and B respectively. Individual models of each of the flowsheet sections are also available. This model is completely connected except for the recycle streams coming from the wet solids drying system and going to both the organic thermal section and to the aqueous processing section. When these final two streams were connected, the ASPEN input translator froze-up so that the model could not be run. This is a problem that will require help from ASPEN Technology. Meanwhile, input streams with compositions very close to these recycle streams are being used to approximate closure.

A number of observations can be made from the ASPEN run results. The F\&OR allowed for an auxiliary fuel stream to be added to the burner for the secondary combustion chamber to provide additional heating capacity to the concentrated organics stream so that complete combustion would take place in the combustion chamber. The amount of auxiliary fuel was not calculated since no energy balances were performed for the F\&OR. The ASPEN run was able to determine the auxiliary fuel requirements by using a design-spec which required the secondary combustion chamber to be adiabatic (at the temperature specified in the F\&OR). An auxiliary fuel rate of $6.5 \mathrm{~kg} / \mathrm{hr}$ was calculated, compared to a flowrate of $5 \mathrm{~kg} / \mathrm{hr}$ for the concentrated organics. Thus the auxiliary fuel requirements are significant. A sensitivity study was performed which helped to determine one of the major users of the auxiliary fuel's heat input. In this study, the flowrate of the wet solids offgas to the secondary combustion chamber was varied from 20 to $160 \mathrm{~kg} / \mathrm{hr}$ and the resulting auxiliary fuel requirements determined. The results can be seen in Figure 12 . The auxiliary fuel requirements varied linearly with the wet solids offgas flowrate, dropping to zero when the wet solids flowrate was less than about $16 \mathrm{~kg} / \mathrm{hr}$. Thus, most of the auxiliary fiel is being used to heat up this offgas stream, which comes in cold and has very little heating value.

The wet-oxidation reactor is another place where some additional heat input is required. Normally one would expect that enough heat is generated in the oxidation reactor to allow the liquid product to be used to preheat the feed, so that no other heat input is required after startup. However, the current simulation does not yield a large enough combustible fraction of the feed stream to provide all of the heat needed, thus requiring a small continuous heat duty from the startup heater. The presence of more water-soluble organics, or less efficient decanters could easily change this situation. It should be noted that the F\&OR assumes a much higher (by an order of magnitude) 


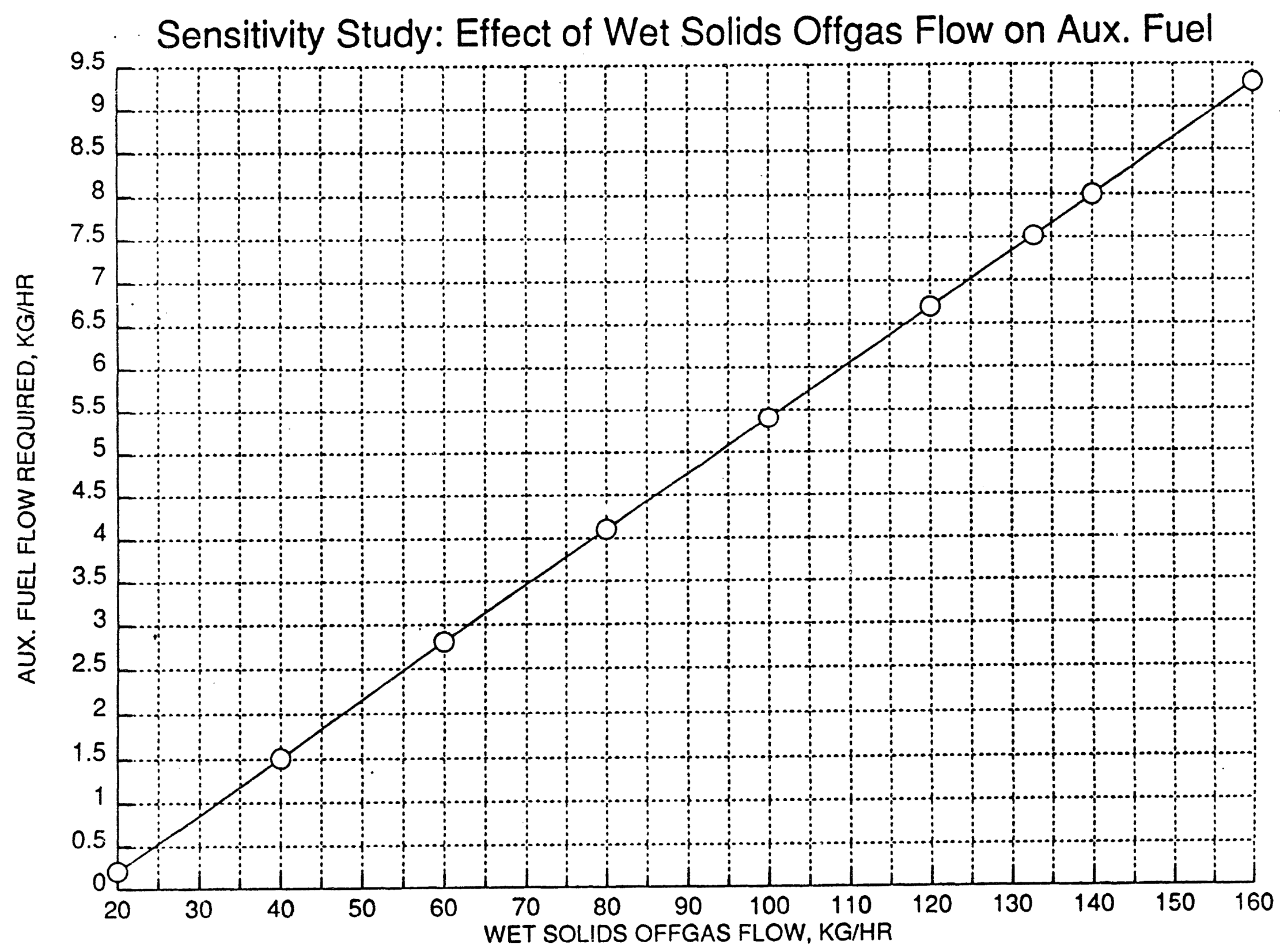

Figure 12: ASPEN sensitivity study results for the auxiliary fuel requirements as a function of the wet solids offgas flowrate. 
amount of entrained organics in the aqueous stream out of the aqueous treatment line decanter than is determined by ASPEN using the model organics described above.

The ultimate goal of a mixed waste treatment facility is to produce environmentally acceptable final waste forms. The solid wastes are encapsulated in various medium (polymer matrix, grout, glass, etc.). The acceptability of these waste forms is based on various strength and leaching tests. Two other output streams which can be evaluated for acceptability from the ASPEN results are the stack gases and the aqueous purge stream. The stack gas compositioii determined from the ASPEN simulation is mostly $\mathrm{N}_{2}$ and $\mathrm{O}_{2}$ as expected with $830 \mathrm{ppm}$ water, $220 \mathrm{ppm} \mathrm{CO}, 0.9 \mathrm{ppm}$ $\mathrm{NO}_{x}$ (consisting of $\mathrm{NO}, \mathrm{NO}_{2}$, and $\mathrm{N}_{2} \mathrm{O}$ ), 0.5 ppm $\mathrm{SO}_{2}, 20 \mathrm{ppb}$ organics, and trace amounts of $\mathrm{CO}$ and $\mathrm{H}_{2}$. The acceptability of this stream will depend on air quality regulations.

Most of the organics in the stack gases originate in the water input to the absorber and scrubber. This water is recycled from the aqueous treatment section. Water from this section is also recycled to the wet solids drying system (to aid in removing the wet solids from the drums and create a slurry). A small purge stream remains $(170 \mathrm{~kg} / \mathrm{hr}$ out of 935 $\mathrm{kg} / \mathrm{hr}$ total coming from the ion exchange column) which could potentially be used elsewhere in the plant or be discharged. The composition of this purge stream from the current ASPEN run includes approximately $0.1 \%$ dissolved $\mathrm{NaCl}$ and $0.8 \% \mathrm{NaOH}$. The caustic comes from the scrubber effluent (approximately $13 \% \mathrm{NaOH}$ ) which could be neutralized as it enters the aqueous treatment system, thereby increasing the $\mathrm{pH}$ of the downstream aqueous streams. The aqueous purge stream from the ion exchange column also contains some dissolved gases and approximately $15 \mathrm{ppm}$ organics. The need for further treatment to reinove some of these components prior to discharge would need to be evaluated.

As mentioned earlier, a second aqueous treatment flowsheet was created in which the ion exchange column was replaced by an evaporator to provide secondary polishing of the aqueous stream. The aqueous purge stream from this process is free of $\mathrm{NaCl}$ and $\mathrm{NaOH}$, but has a 5-fold increase in organics. This is one of the design options which needs to be evaluated further.

On a larger scale, the overall feed and product flowrates of this ASPEN model agree very well with the F\&OR stream table values. Despite the differences between the LANL and LLNL models, these simulation results were strikingly similar. A comparison summary is given in Table 4. The flowrates for all but one of the product streams were within $10 \%$ of each other (the exception being within 16\%). Another interesting point of comparison was of the amount of auxiliary fuel required for the secondary combustion 
Table 4: Comparison of F\&OR, LANL and LLNL MWTP ASPEN model flowrate results for various streams including output streams, final forms (FF) streams, and auxiliary fuel requirements.

FLOWRATE, KG/DAY

\begin{tabular}{lccc}
\multicolumn{1}{c}{ STREAM } & F\&OR & LANL MODEL & LLNL MODEL \\
\hline Clean Water & 22444 & 22408 & 22430 \\
Inerts FF & 3234 & 3193 & 3410 \\
Non-Ferrous Metals FF & 268 & 325 & 271 \\
Ferrous Metals FF & 276 & 275 & 278 \\
Lead FF & 213 & 211 & 214 \\
Recycled Lead & 740 & 735 & 739 \\
Glass FF & 332 & 314 & 338 \\
Thermal Offgas to Stack & 13240 & 16220 & 14508 \\
Auxiliary Fuel & ---- & 205 & 155 \\
Total Organics to Burner & --- & 303 & 280
\end{tabular}


chamber burner. Despite the differences in how the combustibles were defined and in how the reactors were modelled, the auxiliary fuel requirements were within $25 \%$ of each other and most of this difference could be accounted for by a different interpretation of the percentage of organics in labpack and scintillation vial feed streams. The total flowrate of organics being sent to the burner, including auxiliary fuel, are within $8 \%$ for the two models.

\section{POSSIBLE IMPROVEMENTS}

There are a number of places where the Livermore ASPEN model could be improved. First of all, more realistic feed streams definitions would help to better define the process requirements throughout. A number of components are only very loosely defined at this point such as the composition of glass, grout, polymer, and ash. If solids size distribution data were available, ASPEN's solids handling capabilities could be better utilized. The venturi scrubber in the offgas treatment system could be modeled by ASPEN's VENTURI block rather than by a FLASH2 block, the centrifuges could be modeled by a CENTRIFUGE block rather than a black box solids separator (SSPLIT), and the filters could all be more precisely modeled. These more detailed solids blocks also require more detailed equipment specifications which would require additional information or assumptions.

The absorber and scrubber columns have not been optimized at this point as to number of stages or recycle flowrates. Also, the mercury still is currently being modeled as a FLASH 2 block because the liquid portion of the feed is already pure mercury. If the impurities in the mercury feed stream were defined, this block could be replace by a multistage column block (such as RADFRAC).

The wet-oxidation reactor is currently modeled using only high pressure air as the oxidizing agent, and as a Gibbs Free Energy equilibrium reaction. A considerable amount of research has been conducted on more effective oxidizing agents with different reaction conditions. This reaction may be kinetic limited, in which case a different ASPEN reactor model may be more appropriate if kinetics or conversions are known.

The ion-exchange column in the aqueous polishing system is currently being modeled as an ion-remover rather than as an exchange reaction. It would be better modeled as a reactor with appropriate exchange rates given. As mentioned previously, an alternative to the ion-exchange column as the secondary polishing step is an evaporator. This has been successfully modeled in the separate aqueous treatment section flowsheet and could be incorporated in the integrated flowsheet. 
One aqueous reaction which has not been taken into account is the very fast reaction of $\mathrm{NO}_{2}$ with water to form $\mathrm{HNO}_{3}$ along with the associated electrolytes. A previous attempt to include this reaction resulted in convergence problems and was dropped for the time being. It would probably be worthwhile to attempt to add this reaction again.

Another change which could be made would be to add the properties of molten metals and glass to the database in order to more appropriately model the melters. The current model has only solid metal and glass properties so that the heat of fusion is not included in the energy balance. The melters (currently modelled as a heat exchanger and separator) would need to be replaced by reactors in both the heating and cooling stages to convert the solid to the liquid and vise-versa. A 3-phase flash could be placed between the reactors to separate the vapor, slag (assuming appropriate slag components are present), and the molten metal. Similarly, if molten lead is added to the database, the solid lead could be converted to molten lead in the roaster bakeout reactors, then converted back in a separate reactor as the lead is cooled down.

Other pieces of the F\&OR flowsheet could also be added to the LLNL ASPEN model such as the front end solids sorting and drum decontamination processes. Many of these are included in the LANL model and will be part of the combined LANL/LLNL model.

If this model (or a modification) is to be used routinely for case studies and process evaluation it might be worthwhile to try and reduce the CPU time required to run it. The final model takes about 8 hours on a 486-processor based computer. Converging all of the recycle loops definitely takes time, and cutting some of the loops, at least temporarily, might speed up the runs without losing too much information. Manual conversion, by modifying an input stream to be the same as the connecting output stream, can be done to come close to the final solution. Another part of the model which is believed to take-up quite a bit of CPU time is the electrolyte thermodynamic calculations. ASPEN uses the NRTL activity coefficient model, along with an iterative scheme, to determine the phase equilibria. A question has been raised asking whether we can avoid using this time-intensive iterative scheme over and over by creating a table of electrolytic flash results which covers the entire space of conditions expected in the MWTP model, then interpolating this table to perform electrolytic mass balance operations in the MWTP ASPEN model. Once approximate solutions are obtained, the electrolytic package could be reintroduced to perform the final convergence. The details and feasibility of such a scheme would need to be worked out (particularly the interpolation method), and any time savings would need to be evaluated. 


\section{FUTURE WORK}

The melding of the two models into a single model is an effort ongoing as of the time of this writing. This will yield a model with the best of both the LLNL and LANL models. In order to accomplish this, the LLNL model was again dissected into smaller sections and sent to LANL, where appropriate pieces are being added to the LANL model (including the liquid organic stream definitions, the offgas treatment system, and the electrolyte chemistry modelling). The resulting model is one of the largest ever seen by ASPEN technologists. Once this model is completed, it can then be modified to look at the effect of alternative treatments or feed stream compositions. It will also provide the bases for modeling significantly different conceptual flowsheets. Case and sensitivity studies can be performed on the various models to observe the effect of parameter changes and to define operating envelopes.

The radioactive components are not currently included in the ASPEN models. These components can eventually be added to the database and the simulation to enable tracking of these components to their final output streams. The BARIN database, available from ASPEN, is a large inorganic database which contains a number of radioactive components. Cost comparisons between the various flowsheets can be made utilizing ASPEN's costing package.

\section{CONCLUSIONS}

The initial ASPEN modelling effort at both LLNL and LANL has provided us with some very valuable information on the capabilities and limitations of process simulators like ASPEN in the MWTP flowsheet modelling effort. Overall we have found that a process simulator can be a very powerful tool to model a flowsheet from a very low level of detail to a great amount of detail. It can perform mass and energy balances on very highly integrated facilities, and can easily do things like determine the auxiliary fuel requirements. It can perform reactions based on thermodynamic criteria, usersupplied kinetics, or strict stoichiometry. It is flexible enough to allow for minor or even major changes to the flowsheet without a tremendous amount of effort. Finally, it may provide some guidance for cost estimation and comparisons. Overall, ASPEN is proving to be a very valuable part of the MWTP modelling effort. 


\section{REFERENCES}

1) Thompson, T. K., Mixed Waste Treatment Project Functional and Operational Requirements for an Integrated Facility, prepared for Los Alamos National Laboratory under subcontract 9-XY2-Y9590-1, Task 014, August 30, 1992

2) Bechtel, Mixed Waste Treatment Project Process Systems and Facilities Design Study and Cost Estimates, prepared for Lawrence Livermore National Laboratory, September, 1992

3) "Surrogate Waste Recipes for MWIP", communication from John Mayberry of Science Applications International Corp., February 10, 1993 (contact Doug Hoffman at Oak Ridge National Laboratory)

4) Handbook of Chemistry and Physics, 58th Edition, R. C. Weast, Ed., CRC Press, Cleveland, Ohio, 1977, pp D191-207

5) Pemberton, R. C., Mash, C. J., International Data Series, Ser. B, Thermodynamic Properties of Aqueous Organic Systems, Engineering Sciences Data Unit, London, 1978, pp 59-62

6) Lencka, M., Wichterle, I., Fluid Phase Equilibria, 18(3), 245, (1984)

7) Borve, K., Dyvik, F., US Patent \# 4640751, Issue Date 870203

8) Wiklund, J. E., US Patent \# 4443417, Issue Date 840417

9) Allgulin, T., US Patent \# 3849537, Issue Date 741119

10) Steinveit, G., Lead-Zinc-Tin '80, Proc. World Symp. Metall. Environ. Control, J.M. Cigan, et. al. Ed., Metall. Soc. AIME, Warrendale, PA, 1979, pp 85ff

11) Dyvik, F., Extraction Metallurgy '85, Institute of Mining and Metallurgy, London, 1985, pp 189ff 
12) Handbook of Chemistry and Physics, 58th Edition, R.C. Weast, Ed., CRC Press, Cleveland, Ohio, 1977, pp B-131, B-254, D-73

13) Chemical Engineers' Handbook, Sth Edition, R. H. Perry and C. H. Chilton, Ed., McGraw Hill, N.Y., 1973, pp 3-111,122

14) Chase, M. W., Davies, C. A., Downey, Jr., J. R., Frurip, D. J., McDonald, R. A., Syverud, A. N., JANAF Thermochemical Tables, 3rd Edition, Part I, American Chemical Society, 1986, pp 805, 807 
APPENDIX A: ASPEN INPUT FILE FOR THE LLNL MODEL OF THE MWTP BASECASE FLOWSHEET 
APPENDIX B: ASPEN RESULT FILE FOR THE LLNL MODEL OF THE MWTP BASECASE FLOWSHEET 

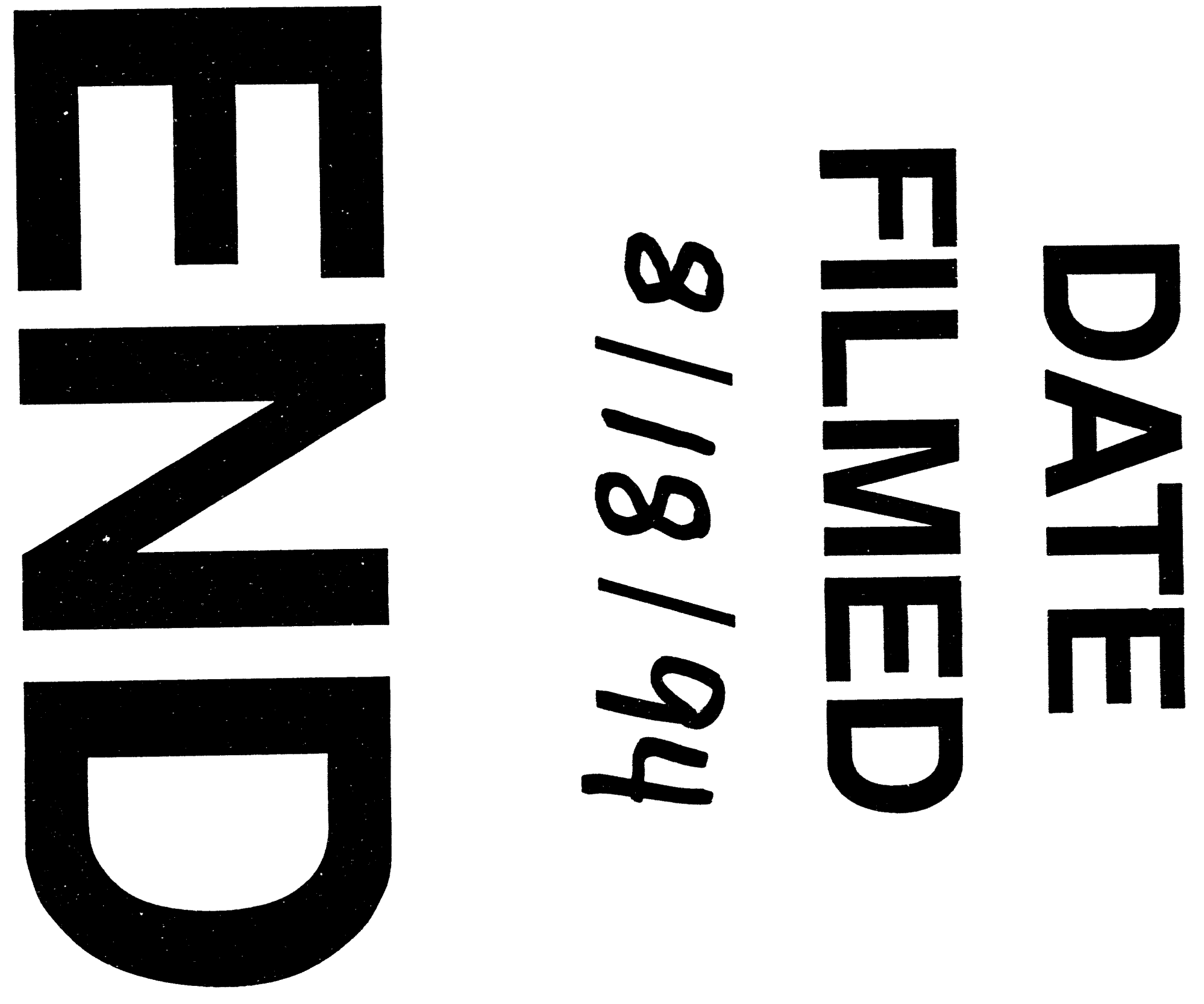
